Portland State University

PDXScholar

Spring 7-20-2015

\title{
Evaluating Global Sensitivity Analysis Methods for Hydrologic Modeling over the Columbia River Basin
}

Maysoun Ayad Hameed

Portland State University

Follow this and additional works at: https://pdxscholar.library.pdx.edu/open_access_etds

Part of the Civil and Environmental Engineering Commons, and the Hydrology Commons Let us know how access to this document benefits you.

\section{Recommended Citation}

Hameed, Maysoun Ayad, "Evaluating Global Sensitivity Analysis Methods for Hydrologic Modeling over the Columbia River Basin" (2015). Dissertations and Theses. Paper 2398.

https://doi.org/10.15760/etd.2395

This Thesis is brought to you for free and open access. It has been accepted for inclusion in Dissertations and Theses by an authorized administrator of PDXScholar. For more information, please contact pdxscholar@pdx.edu. 
Evaluating Global Sensitivity Analysis Methods for Hydrologic Modeling over the Columbia River Basin

\section{by}

Maysoun Ayad Hameed

A thesis submitted in partial fulfillment of the requirements for the degree of

Master of Science

in

Civil and Environmental Engineering

Thesis Committee:

Hamid Moradkhani, Chair

Kelley Barsanti

Mehmet C. Demirel

Portland State University

(C) 2015 
Abstract

Global Sensitivity Analysis (GSA) approach helps to identify the effectiveness of model parameters or inputs and thus provides essential information about the model performance. The effects of 14 parameters and one input (forcing data) of the Sacramento Soil Moisture Accounting (SAC-SMA) model are analyzed by using two GSA methods: Sobol' and Fourier Amplitude Sensitivity Test (FAST). The simulations are carried out over five sub-basins within the Columbia River Basin (CRB) for three different periods: one-year, four-year, and seven-year. The main parameter sensitivities (first-order) and the interactions sensitivities (second-order) are evaluated in this study. Our results show that some hydrological processes are highly affected by the simulation length. In other words, some parameters reveal importance during the short period simulation (e.g. one-year) while other parameters are effective in the long period simulations (e.g. four-year and sevenyear).

Moreover, the reliability of the sensitivity analysis results is compared based on 1) the agreement between the two sensitivity analysis methods (Sobol' and FAST) in terms of highlighting the same parameters or input as the most influential parameters or input and 2) how the methods are cohered in ranking these sensitive parameters under the same conditions (sub-basins and simulation length). The results show that the coherence between the Sobol' and FAST sensitivity analysis methods. Additionally, it is found that FAST method is sufficient to evaluate the main effects of the model parameters and inputs. This study confirms that the Sobol' and FAST methods are reliable GSA methods that can be applied in different scientific applications. Finally, as a future work, we suggest to study 
the uncertainty associated with the sensitivity analysis approach regarding the reliability of evaluating different sensitivity analysis methods.

Keywords: Sensitivity Analysis, Sobol', FAST, Columbia River Basin (CRB) 


\section{Acknowledgement}

I would like to express my deepest gratitude to all those who contribute to make this study successful, and valuable. First, I am very thankful to Almighty God for the blessings, knowledge, and patience that he has been bestowed upon me during my whole life.

Second, I would like to extend my appreciation and gratefulness for my advisor Dr. Hamid Moradkhani for his patience spending his valuable time teaching, guiding, and supporting me by advising and providing all the technical needs to accomplish this research. Also, I would like to thank the rest of my thesis committee members Dr. Kelley Barsanti and Dr. Mehmet C. Demirel, for their valuable efforts editing and improving my thesis work by their valuable suggestions.

Then, I like to thank my family and all my friends who support me all the time especially my friend Yasir M. Saeed. Further, I take this opportunity to give special thanks to The Higher Committee for Education Development in Iraq (HCED) for funding this research. Last but not least, I would like to dedicate my success and progress to my beloved Mother. 
Table of Contents

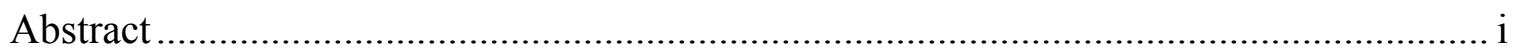

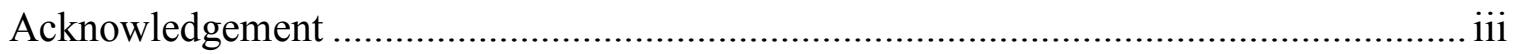

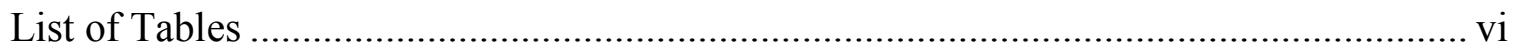

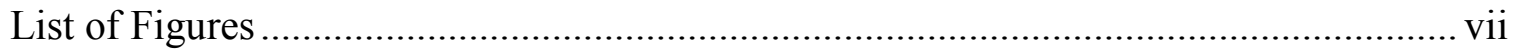

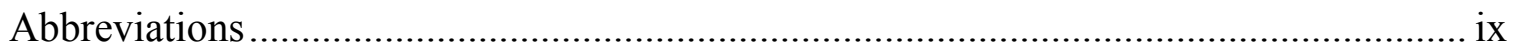

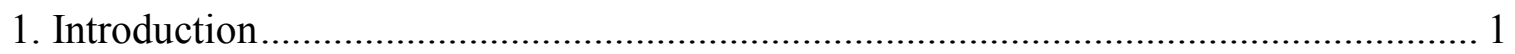

1.1 Background about the Sensitivity Analysis Approach ......................................... 1

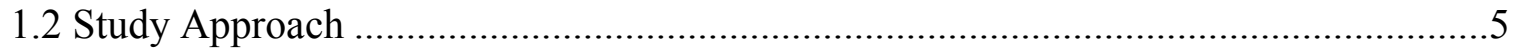

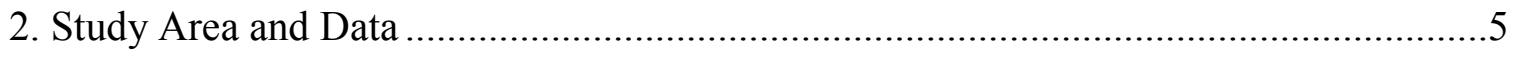

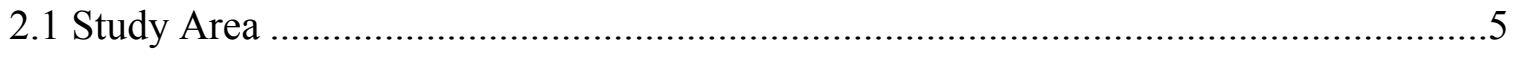

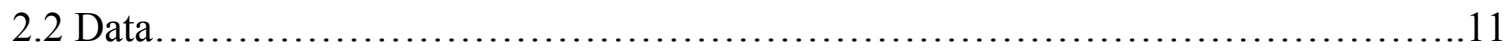

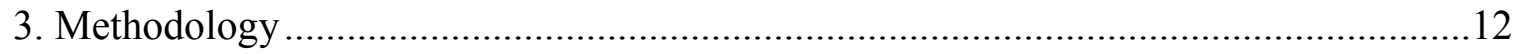

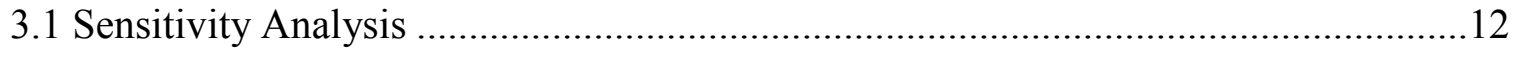

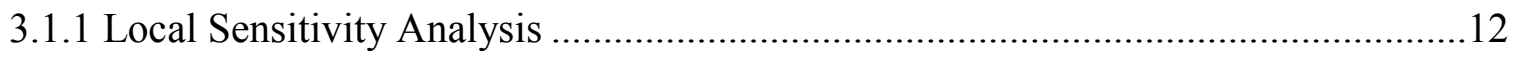

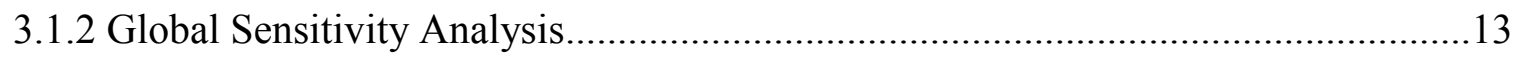

3.1.2.1 Sobol' Global Sensitivity Analysis Method ..................................................14

3.1.2.2 FAST Global Sensitivity Analysis Method ..................................................15

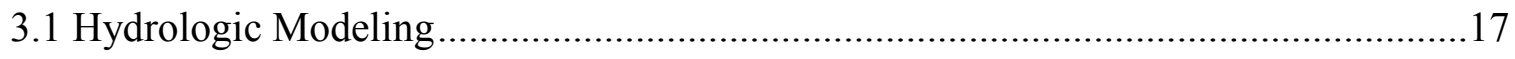


3.1.1 Sacramento Soil Moisture Accounting (SAC-SMA) Model ..................................17

3.1.2 Applying Sobol' and FAST Methods on SAC-SMA model using GSAT ..............19

3.1.2 Monte Carlo and quasi-Monte Carlo Algorithms ..............................................20

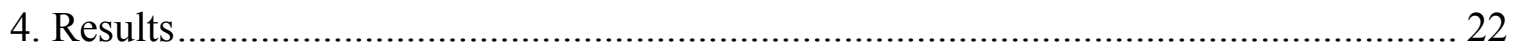

4.1 Importance of Model Input and Parameter Sensitivities (First-Order Effects)............22

4.1.1 Effect of Simulation Length on the Inputs Sensitivity of SAC-SMA Model.......... 22

4.1.2 Comparing the Reliability of Sobol' and FAST Sensitivity Analysis Methods ...... 28

4.2 Effect of Input and Parameter Interactions on the Inputs Sensitivity of SAC-SMA Model.................................................................. 35

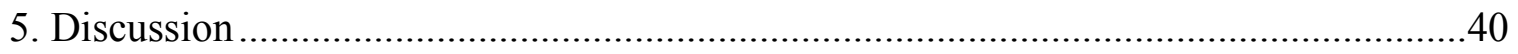

5.1 Physical Interpretations the Consistency of the Sensitivity Analysis Results ............42

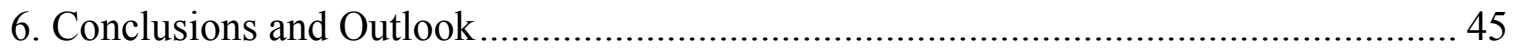

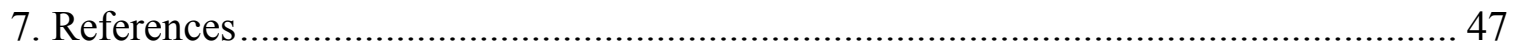




\section{List of Tables}

Table 1 Summary of SAC-SMA parameters 19

Table 2 Comparison of sensitivity evaluation based on the number of mismatching ranking or highlighting of sensitive parameters and input between the two sensitivity analysis methods obtained within four-year evaluation period for the five sub-basins in the CRB. Note that the numbers in the table indicate the rank/order. 33

Table 3 Comparison of sensitivity evaluation based on the number of mismatching ranking or highlighting of sensitive parameters and input between the two sensitivity analysis methods obtained within one-year evaluation period for the five sub-basins in the CRB. Note that the numbers in the table indicate the rank/order. 33

Table 4 Comparison of sensitivity evaluation based on the number of mismatching ranking or highlighting of sensitive parameters and input between the two sensitivity analysis methods obtained within seven-year evaluation period for the five sub-basins in the CRB. Note that the numbers in the table indicate the rank/order. 34

Table 5 Summary of the highest sensitivity indices for the one-year period.

Table 6 Summary of the highest sensitivity indices for the seven-year period 42 
List of Figures

Figure 1 Study Area (Columbia River Basin) .....................................

Figure 2 Topographic map of the Columbia River Basin (CRB) $\ldots \ldots \ldots \ldots \ldots \ldots \ldots \ldots . \ldots$

Figure 3 Conceptual framework of the study................................. 12

Figure 4 Conceptualization of the SAC-SMA, after Burnash et al. (1973)..............17

Figure 5 GSAT Toolbox for performing the Sensitivity Analysis...................20

Figure 6 First-order sensitivity indices evaluated by the Sobol' and FAST sensitivity analysis methods for the one-year simulation period of the five sub-basins: Hungry Horse Sub-basin, Mica Sub-basin, Milner Sub-basin, TW Sullivan Sub-basin, and White Bird

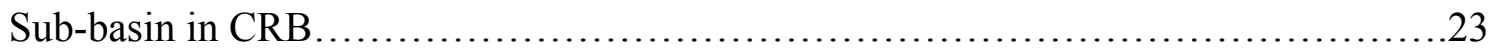

Figure 7 First-order sensitivity indices evaluated by the Sobol' and FAST sensitivity analysis methods for the four-year simulation period of the five sub-basins: Hungry Horse Sub-basin, Mica Sub-basin, Milner Sub-basin, TW Sullivan Sub-basin, and White Bird Sub-basin in CRB................................................ 24

Figure 8 First-order sensitivity indices evaluated by the Sobol' and FAST sensitivity analysis methods for the seven-year simulation period of the five sub-basins: Hungry Horse Sub-basin, Mica Sub-basin, Milner Sub-basin, TW Sullivan Sub-basin, and White

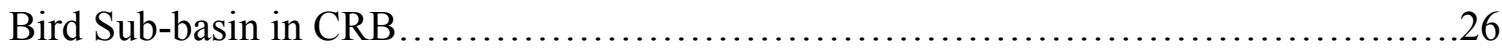

Figure 9 Parameter sensitivity calculated with the Sobol' and FAST sensitivity analysis methods for five sub-basins for different simulation lengths: Oct 2000-Oct 2001, Oct 2000-Oct 2004, and Oct 2000-Oct 2007 
Figure 10 Difference between sensitivity indices of FAST and Sobol' methods during the period of (Oct 2000-Oct 2001) ............................................

Figure 11 Difference between sensitivity indices of FAST and Sobol' methods during the

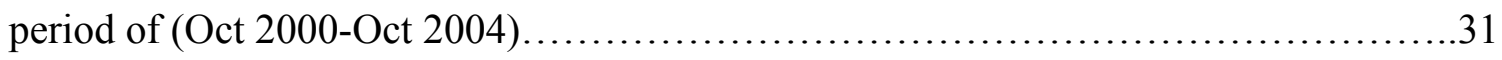

Figure 12 Difference between sensitivity indices of FAST and Sobol' methods during the

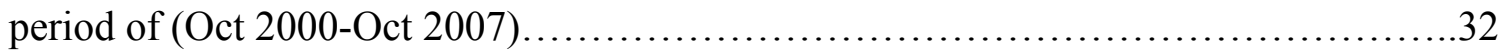

Figure 13 Parameters interactions calculated by the Sobol' (second-order) method for (15) inputs during the one-year simulation period for the five sub-basins of CRB.......37 Figure 14 Parameters interactions calculated by the Sobol' (second-order) method for (15) inputs during the seven-year simulation period for the five sub-basins of CRB.....38 Figure 15 Parameters interactions calculated by the Sobol' (second-order) method for (14) inputs during the seven-year simulation period for the five sub-basins of CRB.....39 


\section{Abbreviations}

$\begin{array}{ll}\text { SA } & \text { Sensitivity Analysis } \\ \text { LSA } & \text { Local Sensitivity Analysis } \\ \text { GSA } & \text { Global Sensitivity Analysis } \\ \text { FAST } & \text { Fourier Amplitude Sensitivity Test } \\ \text { CRB } & \text { Columbia River Basin } \\ \text { ANOVA } & \text { Analysis of Variance } \\ \text { SAC-SMA } & \text { Sacramento Soil Moisture Accounting } \\ \text { GSAT } & \text { Global Sensitivity Analysis Toolbox } \\ \text { USA } & \text { United States of America } \\ \text { OAT } & \text { One-At-a-Time } \\ \text { D } & \text { Dimension } \\ \text { S } & \text { Sobol' or FAST Sensitivity Index } \\ \text { Var } & \text { Variance } \\ \text { NWS } & \text { National Weather Service } \\ \text { RFCs } & \text { River Forecast Centers }\end{array}$




\section{Introduction}

\subsection{Background about the Sensitivity Analysis Approach}

Computer-based models have a vital trend in different science and engineering aspects in recent decades. As a result of developing more complex hydrological models, reliable statistical and mathematical methods are required to enhance the modeling precision (Ebtehaj et al., 2010). In hydrological field, there is what is known as a conceptual model that its parameters are linked indirectly to the physical properties of the real-world case. Also, since these parameters are not visible, the calibration is needed to simulate the model outputs to match the observations (Gan et al., 2014). Some of these models are complex models that have a large number of parameters (e.g. more than 10 parameters), which in turn influence the model performance (Gan et al., 2014). Also, the large number of parameters requires a large number of model runs to find an optimum in solution space (Dobler and Pappenberger, 2013). Massmann and Holzmann (2012) state that the model of high dimensionality, has large number of parameters, is preferable since it gives more flexibility to set its parameters to fit the observed data. Nevertheless, the problem of overparameterization will occur and increases model complexity. However, the calibration is a hard task for some models, especially for a non-linear model of 10 or more parameters (Li et al., 2013). Furthermore, there is another reason for model complexity which is the uncertainty associated with the model inputs (parameters, forcing data, initial conditions) and model structure. For the aforementioned reasons, the interest of the modelers is to simplify the complexity of the model using different techniques. One of the most recently popular ways is the sensitivity analysis (SA) methods. 
The basic idea is to apply a statistical method on the model inputs to specify the most influential inputs in that specific model. Sensitivity analysis (SA) is a simple way to attribute the variation of the model output to partial variations in the model inputs (Shin et al., 2013). Evidently, the researchers concluded that sensitivity analysis (SA) technique improves the model results by reducing its variance. To do so, the unimportant parameters or inputs are fixed as constant values, whereas only the important ones are included in the calibration procedure as an example (Song et al., 2015).

In research, there is a remarkable interest to study the SA as it enhances our understanding about the model behavior, the joint effects between different model inputs, and how all these are connected to the real-world (Saltelli et al., 1999). Nevertheless, the computational cost is still a critical factor in applying the SA methods in different applications (Razavi and Gupta, 2015). Thus, the effectiveness and efficiency are both required to achieve the modeler's goal.

In general, SA can be classified into two classes: local sensitivity analysis methods (LSA) and global sensitivity analysis (GSA) methods. The main difference between these two groups that the LSA evaluates the sensitivity at specific point in the model space, while the GSA evaluates the sensitivity over the entire space (Massmann and Holzmann, 2012). The LSA evaluation depends on the estimated derivatives at certain points in the parameter space, however, the selected points may affect the sensitivity analysis results under highly uncertain effects. Therefore, these methods are only applied in linear applications. On the other hand, the GSA methods account for including the whole model space to estimate the sensitivity of the inputs. Moreover, all the inputs are altered at the same time considering 
the interactions between the model inputs (Lilburne and Tarantola, 2009). Since most of the hydrological models are non-linear and influenced by the interactions between the inputs, the GSA methods are more proper than LSA to use in these applications. There are many GSA methods in the literature, however two reliable methods, widely used in the research, are: Sobol' method (Sobol', 1993) and Fourier amplitude sensitivity test (FAST) (Cukier et al., 1978). These methods are variance-based methods that apportion the total variance in the model output to partial variances in the inputs following the ANOVA-like decomposition analysis (Reusser et al., 2011). The main effects (first-order sensitivity) can be evaluated in both methods, however, FAST is more efficient than Sobol' in terms of computational expense. On the other hand, Sobol' is effective in estimating the higher interaction effects (second-order sensitivity or more) by calculating the total sensitivity of each parameter, whereas FAST is limited in this aspect (Saltelli et al., 1999). Estimating the joint effects between the model parameters can highlight the model processes that are considerably connected (Nossent et al., 2011). Furthermore, an attractive property of Sobol' method is its ability to estimate the partial variance of each input directly by using Monte Carlo integral (Confalonieri et al., 2010).

The application of Sobol' method has been avoided in hydrology due to its drawback in the computational needs (Zhan et al., 2013). However, it is considered as a robust method that comes through the dimensionality dilemma. Therefore, in this study the aforementioned SA methods (Sobol' and FAST) are conducted on the conceptual hydrologic model: Sacramento Soil Moisture Accounting Model (SAC-SMA) to evaluate the relevance of its parameters and the precipitation as the only forcing input in the model. 
The SAC-SMA model is a popular non-linear hydrological model that is widely used in research. The model considered as a complex model with 16 parameters, thus this model demands a high number of model evaluations to cover the entire model space. The focus of the current study is to investigate three of factors that influence the sensitivity analysis results. The first factor is the effect of the simulation length, so the sensitivity analysis is evaluated for three different periods: one-year (Oct 2000-Oct 2001), four-years (Oct 2000Oct 2004), and seven-years (Oct 2000- Oct 2007). Secondly, the reliability and robustness of the applied sensitivity analysis method and thus two GSA methods are compared. Finally, the effect of different geographic locations on the sensitivity analysis, and thus five sub-basins with different characteristics from the Columbia River Basin (CRB) are included in this study.

The thesis is organized as follows: Introduction and study approach are described in chapter 1; study area and datasets are explained in chapter 2; methodology of sensitivity analysis, hydrological modeling, and the application of sensitivity analysis methods on the hydrological model using GSAT are described in chapter 3; results are provided in chapter 4; discussion and physical interpretations and the consistency of the sensitivity analysis results are covered in chapter 5; and finally conclusion and outlook are summarized in chapter 5 . 


\subsection{Study Approach}

The goal of this study is to evaluate two global sensitivity analysis (GSA) methods (Sobol' and FAST) by applying these methods on a hydrological model (Sacramento Soil Moisture Accounting Model). The study area is the Columbia River Basin (CRB) in the USA including the British Columbia in the Canadian part. The study will cover five different sub-basins within the CRB during three different time periods.

\section{Study Area and Data}

\subsection{Study Area}

The Columbia River Basin (CRB) is one of the largest rivers within the United States. The CRB area is about 258,500 square miles, with 85 percent of the basin area lies in USA and the rest in Canada (Davidson and McClain, 2014). The river passes through seven states in the western part of the USA (Washington, Oregon, Idaho, Montana, Wyoming, Nevada, and Utah), and the western part of Canada (British Columbia) as shown in Figure 1. Geographically, most of the area of the basin lies between the Rocky Mountains (East and North) and the Cascade Mountains (West). Figure 2 displays the topography along the $\mathrm{CRB}$, which plays a major role controlling the precipitation within the basin. The climate over the basin experience wet weather conditions in the western parts and arid conditions in the south-eastern parts (Matheussen et al., 2000).

From a hydrological stand point, the CRB is mainly governed by the snow accumulation in winter season and snow melt in spring season (Hamlet and Lettenmaier, 1999). Five sub-basins of the CRB are the focus of this study. Four of them distributed 
throughout the USA (Hungry Horse, White Bird, Milner, and TW Sullivan) and the last one (Mica) lies in Canada.The Hungry Horse sub-basin located in western Montana. The South Fork of the Flathead River, which originates nearby the Continental Divide in the USA, flows through the Hungry Horse sub-basin (Bureau of Reclamation, 2012). The White Bird sub-basin lies in western Idaho in which the Salmon River, originating in the central and eastern mountains of Idaho, flows through the sub-basin (Sridhar et al., 2013). The Snake River, the $12^{\text {th }}$ largest river in the USA and the largest tributary of the Columbia River, flows through the Milner sub-basin in southern Idaho. The forth sub-basin is the TW Sullivan sub-basin which lies in the north-western part of Oregon. The Willamette River, the $13^{\text {th }}$ largest river in the continental USA, flows in the TW Sullivan sub-basin (Halmstad et al., 2013). The last region of interest is the Mica sub-basin in Canada which is the main tributary of the CRB in British Columbia (Jost et al., 2012).

The reason behind choosing these five sub-basins is to cover different regions in the CRB. Some of these sub-basins experience the same climate and topography conditions while other sub-basin do not. For example, the Mica sub-basin lies in the Northern part of the CRB (snow dominated) while TW Sullivan sub-basin lies in the Western part of it (rainfed area). 


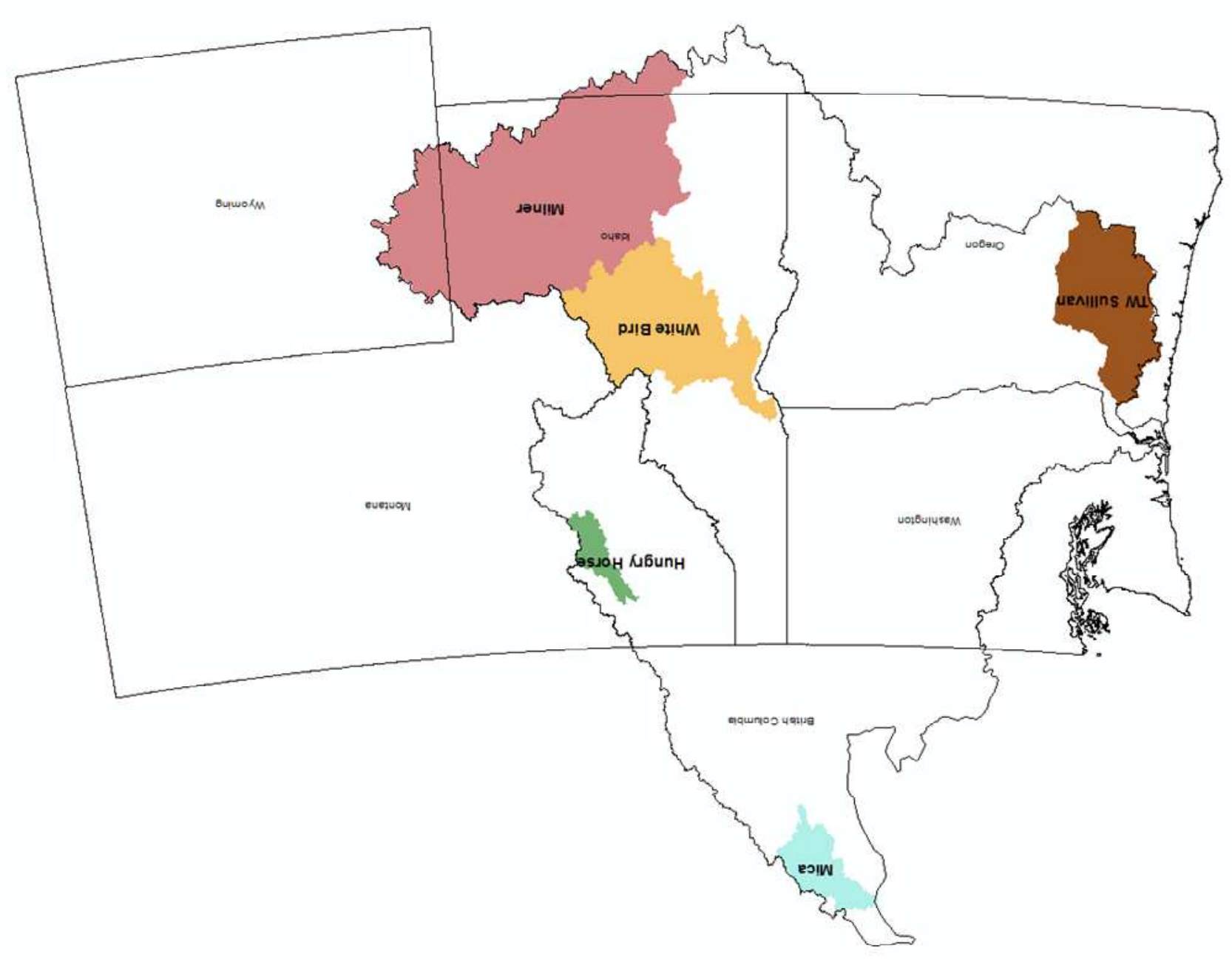




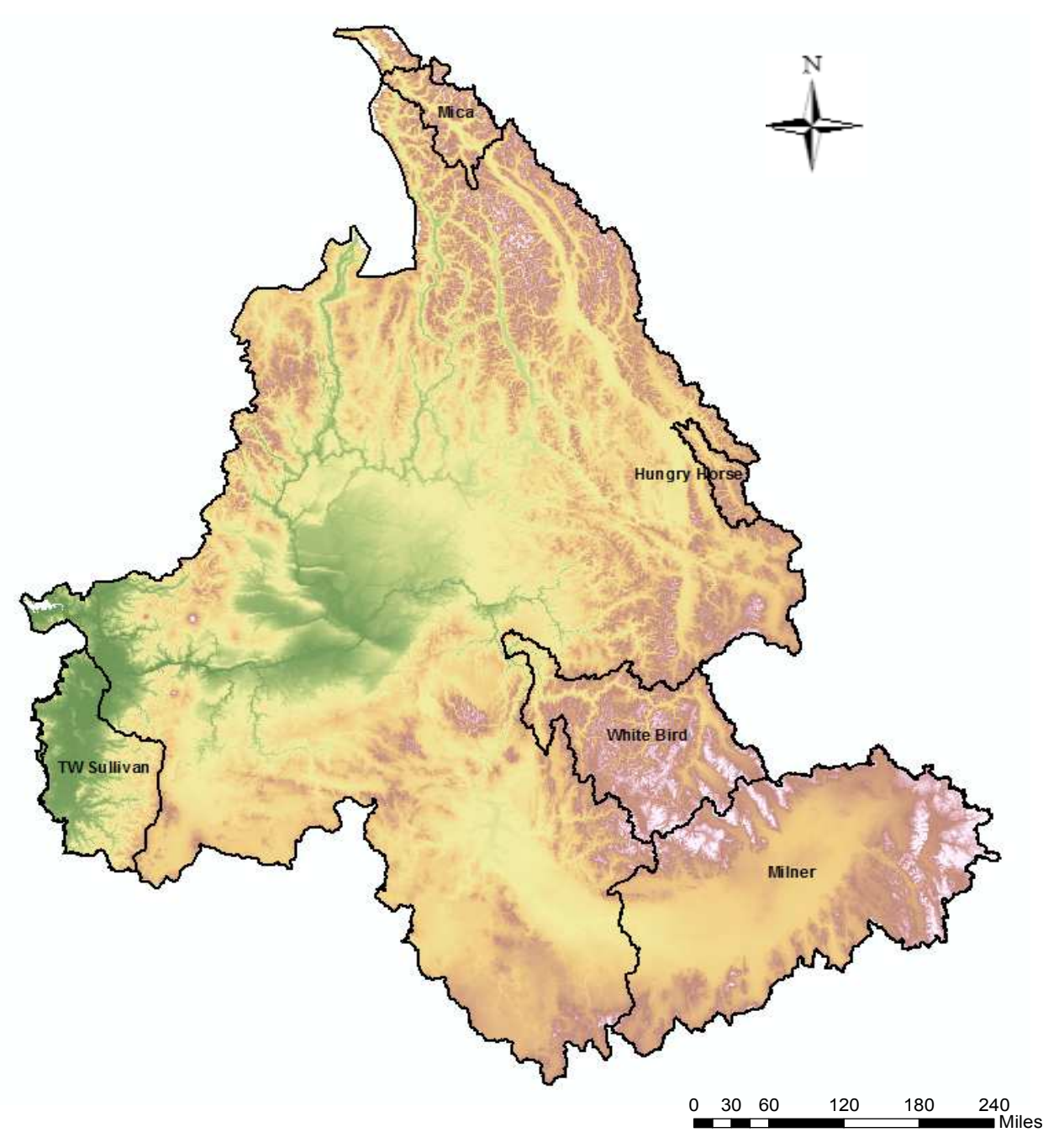

Figure 2 Topographic map of the Columbia River Basin (CRB)

\section{Mica Sub-basin}

The Mica sub-basin, which is considered as a main tributary of the CRB in British Columbia in Canada, covers an area of $20,742 \mathrm{~km}^{2}$ (Figure 1). The mean annual precipitation is $1075 \mathrm{~mm}$; about $70 \%$ of it falls as snow. In winter, the mean annual temperature reaches about $-9.4{ }^{\circ} \mathrm{C}$ and increases in summer season to $13.4{ }^{\circ} \mathrm{C}$. As a result 
of climate change effects, the glaciers in the sub-basin have decreased by $101 \mathrm{~km}^{2}$ within the period from 1985 to 2000 . Also, about $80 \mathrm{~km}^{2}$ of glaciers within the sub-basin disappeared during the period (2000-2005) (Bolch et al., 2010). The land cover of the subbasin varies between different kinds of plants like (alpine areas, range lands, agricultural lands, recently logged areas) and forests (Jost et al., 2012).

\section{Hungry Horse Sub-basin}

The Hungry Horse sub-basin, which has a length of 34 miles, lies on the South Fork of the Flathead River. The sub-basin is located in the Rocky Mountains and is surrounded by 25 mountains, covering a drainage area of about 23,800 acres (Figure 1). The sub-basin lies at elevation of $900 \mathrm{~m}$ in a rainfed forested area in Montana (Risley et al., 2011). Hungry Horse Dam was built in 1953 and is about 15 miles from Glacier National Park in the west and 44 miles from Canada. During spring season, the Hungry Horse sub-basin is used to store the snowmelt and fill a pool of elevation 3560 feet. In contrast, in fall and winter seasons, the sub-basin is used for power generation and therefore, is discharged to prepare it for the flood management in spring time (State of Montana, 2011).

\section{Milner Sub-basin}

The Milner sub-basin covers an area of 4000 acres, and is located in the southeastern part of Idaho, western Wyoming State, and northern of Utah and Nevada States. The Snake River, the largest tributary of the Columbia River, passes through the sub-basin. 
The capacity of the sub-basin is about 36,300 acre feet. For power generation and irrigation purposes, Milner Dam was constructed in south central Idaho. The Rocky Mountains, covered by snow in winter, lie on the east side of the sub-basin as shown in Figure 2. The climate conditions vary in the sub-basin from snowy, cold in the eastern side to semi-arid and arid conditions in the western side. The arid portions of the sub-basin are mostly agricultural areas with low moisture, therefore, these areas are mainly irrigated by groundwater (Hoekema and Sridhar, 2011).

\section{White Bird Sub-basin}

The White Bird sub-basin, 13,421 square miles, is located in Idaho. The Salmon River, River of No Return, flows through the sub-basin to the North to merge with the Snake River in Idaho. Most of the sub-basin area lies in the Rocky Mountains which provides the Salmon River with snowmelt water (Figure 2). The forests and grasslands dominate the vegetation in the sub-basin. Depending on the elevation within the sub-basin, $50 \%$ of the precipitation in winter season is snow with a depth varying from 50 to $300 \mathrm{~cm}$ (Sridhar et al., 2013).

\section{TW Sullivan Sub-basin}

The TW Sullivan sub-basin is located in Oregon City at the Willamette Falls which is mostly forested as shown in Figure 2. The Willamette River has a drainage area of about $31,080 \mathrm{~km}^{2}$ and length of about $474 \mathrm{~km}$ (Fierke and Kauffman, 2005). The climate 
conditions in the area are cold and wet in winter season and warm and dry in summer season (Halmstad et al., 2013; Chang et al., 2011; Chang and Jung, 2010). The mean precipitation over the sub-basin is about $110 \mathrm{~cm} /$ year and the mean temperature varies between $4.4-26.7^{\circ} \mathrm{C}$ (Fierke and Kauffman, 2005).

\subsection{Data}

The observed daily meteorological dataset of the Columbia River Basin (CRB), from University of Washington (Livneh et al., 2013), is used in this study. The dataset is for five sub-basins, which have different hydroclimatic conditions and geographic locations, four of them are in the USA and one in Canada. The dataset is gridded at a 1/16 degree spatial resolution $\left(6^{*} 6 \mathrm{~km}\right)$ for the period $(1915-2011)$. The dataset provides information of four meteorological variables: precipitation, maximum and minimum temperature, and wind speed. For this study, the potential evaporation variable is estimated from monthly normal potential evaporation on the 15 th of each month, then linearly interpolated to all other time-steps. The monthly normals are estimated by the National Weather Service based on monthly pan evaporation rates (Farnsworth and Thompson, 1983). 


\section{Methodology}

\subsection{Sensitivity Analysis}

The role of SA can help model users to interpret the outcomes and distinguish the active parts of the model, and thus the model can be improved (Confalonieri et al., 2010). Sensitivity analysis provides information that address the relationships between individual model inputs (Confalonieri et al., 2010), which can be the models parameters, forcing data, and initial conditions.

Figure 3 Figure 3 shows a conceptual framework of the study. The first step is to define the sub-basins over the CRB and define the hydrologic model (SAC-SMA) input and parameters with their acceptable ranges. The second step is to apply the sensitivity analysis methods on the SAC-SMA model: Sobol' and FAST. Finally, the output will be the Sobol' and FAST indices. This section covers: a brief overview of the Local Sensitivity Analysis (LSA) and Global Sensitivity Analysis (GSA) methods, the Sobol' and FAST methods, the hydrological modeling, GSAT toolbox, and sampling algorithms.

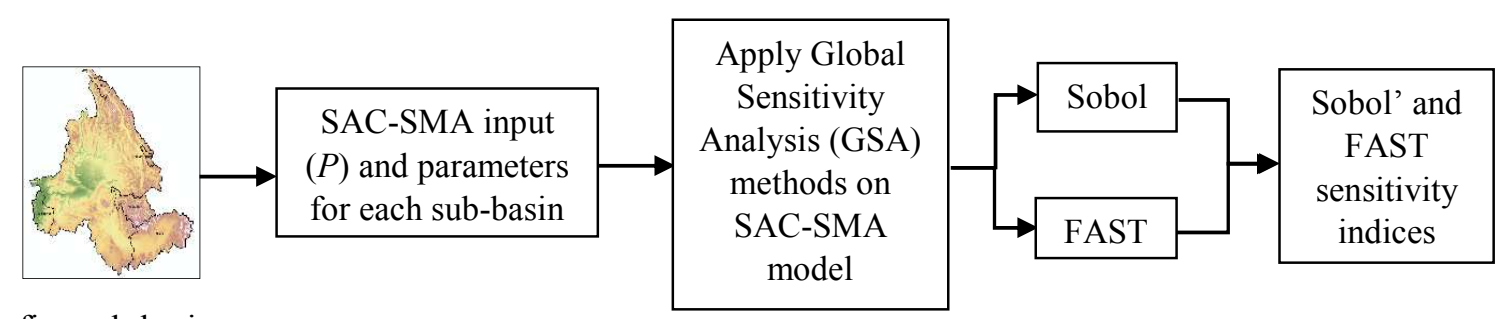

Define sub-basins

Figure 3 Conceptual framework of the study

\subsubsection{Local Sensitivity Analysis}

This method is known as a One-At-a-Time (OAT) Sensitivity Analysis that estimates the sensitivity at one point in the parameter space (Massmann and Holzman, 2012). The benefit of using LSA that it requires a few model runs and gives a reliable outcome when the model behavior is linear (Peeters et al., 2014). On the other hand, the drawback of this method that the interaction effects are not considered. In reality, the non-linearity of the 
hydrological models show that combining the main parameter effect and its interactions with other parameters is needed to capture the model response behavior. For these reasons, the LSA is inapplicable in non-linear problems (Sun et al., 2012). In conclusion, Global Sensitivity Analysis is more appropriate than the Local Sensitivity Analysis (LSA) for the non-linear hydrological applications.

\subsubsection{Global Sensitivity Analysis}

The attractiveness of this method is that the parameter space is explored within a specific region and the parameter sensitivity is estimated globally by varying all the parameters at the same time in the parameter space (Saltelli et al., 1999). Li et al. (2013) state that Global Sensitivity Analysis (GSA) is better than Local Sensitivity Analysis (LSA) in which the LSA traps in type I or type II errors, for example: the sensitive parameters are distinguished as insensitive (type I error) or the insensitive ones are sensitive (type II error). Using complex models like the 2-D hydrological models, which have many inputs, the GSA is preferred over the LSA to use to simplify the model complexity (Cannavó, 2012).

In the literature, there are many GSA methods, however, Sobol' Sensitivity Analysis and Fourier Amplitude Sensitivity Test are the most robust approaches (Cannavó, 2012). These methods are also called variance-based methods and are applied in many different studies (Lilburne and Tarantola, 2009). In this study, Sobol' and FAST SA methods are used, however, the focus is more on Sobol' SA, since this method is able to estimate the sensitivity of higher order (interactions between the parameters). 


\subsubsection{Sobol' Global Sensitivity Analysis Method}

Sobol' GSA is one of the most robust quantitative methods to calculate the sensitivity indices of the model inputs (van Werkhoven et al., 2008). By using Sobol' GSA, the main effect "first-order sensitivity index" by Sobol'(1990) and total effect of the input can be quantified. Also, the interactions between the model inputs can be calculated if there is any. However, because the Sobol' interaction indices increase exponentially with the number of parameters, only the first and second order Sobol' effects are studied (Gan et al., 2014). This approach by Sobol' (1990) is based on the Analysis of Variance (ANOVA) decomposition to calculate the variance of the inputs (Cannavó, 2012). The decomposition is as $V=\sum_{i=1}^{n} V_{i}+\sum_{1 \leq i<j \leq n} V_{i j}+\cdots+V_{1,2, \ldots, n}$, where $n$ is the number of variables, and $V_{i}$ is the explained part of outcome variance by the $i$ th variable, $V_{i j}$ is the explained part of outcome variance by the interaction between the $i$ th and $j$ th variables, $V_{l, 2, \ldots, n}$ is the explained part of outcome variance by the interaction of all the variables (Li et al., 2013). Furthermore, Li et al. (2013) state that the Sobol' sensitivity index is $S i_{1}, \ldots, i_{s}=V i_{1}, \ldots, i_{s} / V$, where $V i_{1}, \ldots, i_{s}$ is the variance of $\left(i_{1}, \ldots, i_{s}\right)$, and $s$ is the dimension of Sobol' index. The Sobol' main effect (first-order effect) and interaction effect (second-order effect) can be obtained by Eq.(1), Where the sum of all the non-negative values in Eq.(1) is equal to one (Sobol, 2001).

$$
\sum_{i=1}^{n} S_{i}+\sum_{1 \leq i<j \leq n} S_{i j}+\cdots+S_{1,2, \ldots, n}=1
$$

Another expression presented by Lilburne and Tarantola, (2009) of the Sobol' first-order indices can be written as: 


$$
S_{i}=\frac{\operatorname{Var}\left[E\left(Y \mid X_{i}\right)\right]}{\operatorname{Var}(Y)}
$$

Where, the term $\operatorname{Var}\left[E\left(Y \mid X_{i}\right)\right]$ is the expected conditional variance of the model $\operatorname{output}(Y)$. While the term $\operatorname{Var}(Y)$ is the unconditional variance of the model $(Y)$.

The Sobol' index is a unitless index varies between zero and one. Higher values close to one, indicate higher variances showing more important parameters which are highly affecting the model output variance. In other words, the value of the index will show the degree of importance of that parameter. Although Sobol' is a robust quantitative method that valuable information about the model inputs can be obtained, it has some drawbacks like any other method. The Sobol' procedure needs a large number of model runs (e.g. $\left.>10^{4}-10^{5}\right)(\mathrm{Li}$ et al., 2013). Therefore, since Sobol' requires sampling the parameter space, it is considered a computationally intensive method (Wainwright et al., 2014). In this study, $10^{4}$ model runs are conducted to evaluate the sensitivity of 15 variables, 14 of them are SAC-SMA model parameters and one input (precipitation).

\subsubsection{FAST Global Sensitivity Analysis Method}

The Fourier Amplitude Sensitivity Test (FAST) is another popular robust GSA method. The method was first presented by Cukier et al. (1973). The basic concept behind this method is to convert the multi-dimensional integral into a one-dimensional integral by applying the ergodic theorem (Gan et al., 2014). Ergodic theory is a mathematical study of a system behavior that develops over time (Dajani and Dirksin, 2008). Once again, the FAST procedure follow the ANOVA decomposition of the function like Sobol' method. 
Moreover, the model output can be extended into a Fourier series, so that the variance expected of the model output can be estimated (Reusser et al., 2011). Using Bayesian rule, the FAST index is given by Saltelli et al, (1999):

$$
S=\frac{\operatorname{Var}_{X}[E(Y \mid X)]}{\operatorname{Var}(Y)}
$$

Where $Y$ is the output, $X$ is the input, $E(Y \mid X)$ is the expected value of $Y$ given the input $X$, and $\operatorname{Var}_{X}$ is the variance that is accounted for all the possible values of the input $X$.

The evaluation of the analysis is based on the sum of the input indices: the closer to 1 gives the better result (Saltelli et al, 1999), considering that the FAST indices also are dimensionless indices vary between zero and one. The FAST method can estimate the main effect of variance contribution of each input to the output variance (Saltelli et al., 1999), and thus FAST indices are equivalent to the Sobol' first order indices (Cannavó, 2012). FAST method, unlike the Sobol' method, is unable to estimate the higher-order interaction terms. Since most of the hydrological applications have non-linear relationship between the inputs, considering the effects of interactions between these inputs is important (Zhan et al., 2013). Therefore, the Sobol' method is more practical than FAST for non-linear applications that it is able to evaluate the higher order interactions between the model inputs. 


\subsection{Hydrologic Modeling}

\subsubsection{Sacramento Soil Moisture Accounting (SAC-SMA) Model}

The Sacramento (SAC-SMA) model, one of the most popular conceptual hydrological models, was first introduced by Burnash et al. (1973).

Figure 4 shows the SAC-SMA model and its parameters. It is mainly used as a rainfall-runoff model by the National Weather Service (NWS) River Forecast Centers (RFCs) in USA to forecast rivers (van Werkhoven et al., 2008; Van Werkhoven et al., 2009; DeChant and Moradkhani, 2012; Shin et al., 2013). Nowadays, the SAC-SMA model is used also for long term predictions as described by Shin et al., (2013). Furthermore, the model is also known in regionalization studies (Vaze et al., 2010). It should be noted that the lumped version of SAC-SMA model is applied in this study. The lumped hydrologic model simulates the streamflow only at the outlet of the basin (Moradkhani and Sorooshian, 2008).

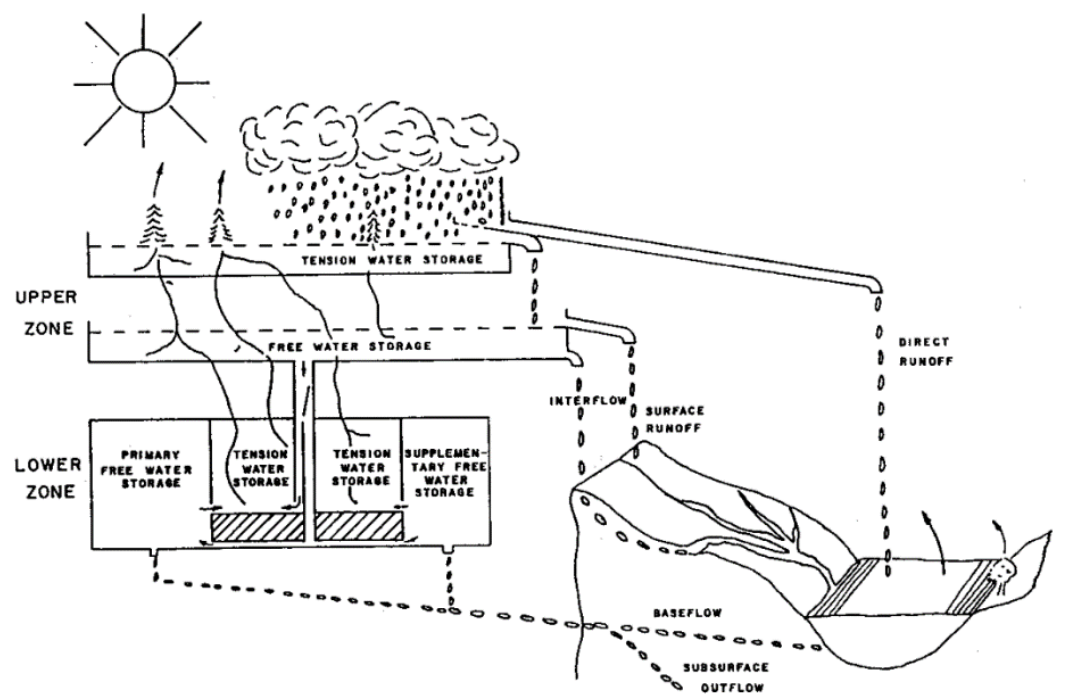

Figure 4 Conceptualization of the SAC-SMA, after Burnash et al. (1973) 
3 of the 16 SAC-SMA model parameters (RIVA, SIDE, and RSERV), which stand for (riparian vegetation area, ratio of deep recharge to channel baseflow, and fraction of lower zone free water not transferrable to lower zone tension water, respectively), are set to have constant values (Shin et al., 2013). Another parameter is added in this study which the routing parameter, which route the quick flow component with three linear Nash Cascade sub-basins. And finally, the model input (the precipitation) is also included to have a total number of 15 input and parameters. Only the 14 SAC-SMA model parameters are presented in Table 1 with their acceptable ranges used in the SA process (Shamir et al., 2005). The model consists of two soil layers: upper soil layer and lower soil layer. The upper layer represents the short-term storage near the soil surface, while the lower one represents the long-term storage as baseflow play a role (Najafi et al., 2011). 
Table 1 Summary of SAC-SMA parameters.

\begin{tabular}{|cclc|c|}
\hline Parameter & Unit & \multicolumn{1}{c|}{ Description } & $\begin{array}{c}\text { Range } \\
\text { (min-max) }\end{array}$ \\
\hline UZTWM & $\mathrm{mm}$ & Upper zone tension water maximum storage & $1.0-150.0$ \\
\hline UZFWM & $\mathrm{mm}$ & Upper zone free water maximum storage & $1.0-150.0$ \\
\hline UZK & day ${ }^{-1}$ & Upper zone free water lateral depletion rate & $0.1-0.5$ \\
\hline PCTIM & & Impervious fraction of the basin & $0.0-0.1$ \\
\hline ADIMP & $\mathrm{mm}$ & Additional impervious area & $0.0-0.4$ \\
\hline ZPERC & --- & Maximum percolation rate & $1.0-250.0$ \\
\hline REXP & --- & Exponent of the percolation equation & $1.0-5.0$ \\
\hline LZTWM & $\mathrm{mm}$ & Lower zone tension water maximum storage & $1.0-1000.0$ \\
\hline LZFSM & $\mathrm{mm}$ & Lower zone free water supplemental maximum storage & $1.0-1000.0$ \\
\hline LZFPM & $\mathrm{mm}$ & Lower zone free water primary maximum storage & $1.0-1000.0$ \\
\hline LZSK & day ${ }^{-1}$ & Lower zone supplemental free water depletion rate & $0.01-0.25$ \\
\hline LZPK & day ${ }^{-1}$ & Lower zone primary free water depletion rate & $0.0001-0.025$ \\
\hline PFREE & ---- & Fraction of water percolating from upper zone to the lower zone & $0.0-0.6$ \\
\hline kq & day & Route quick flow component with 3 linear basins in series & $0.2-0.25$ \\
\hline & & & \\
\hline
\end{tabular}

\subsubsection{Applying Sobol' and FAST Methods on SAC-SMA model using GSAT}

Cannavó (2012) developed a Matlab toolbox named GSAT (Global Sensitivity Analysis Toolbox). This toolbox is a set of code routines for estimating the sensitivity indices of Sobol' (first and second orders) and FAST (main effects) SA methods. It is found that the algorithm is time consuming due to the fact that it is affected exponentially by the number of inputs (Cannavó, 2012). The logic flowchart as presented by Cannavó (2012) is shown in Figure 5. 


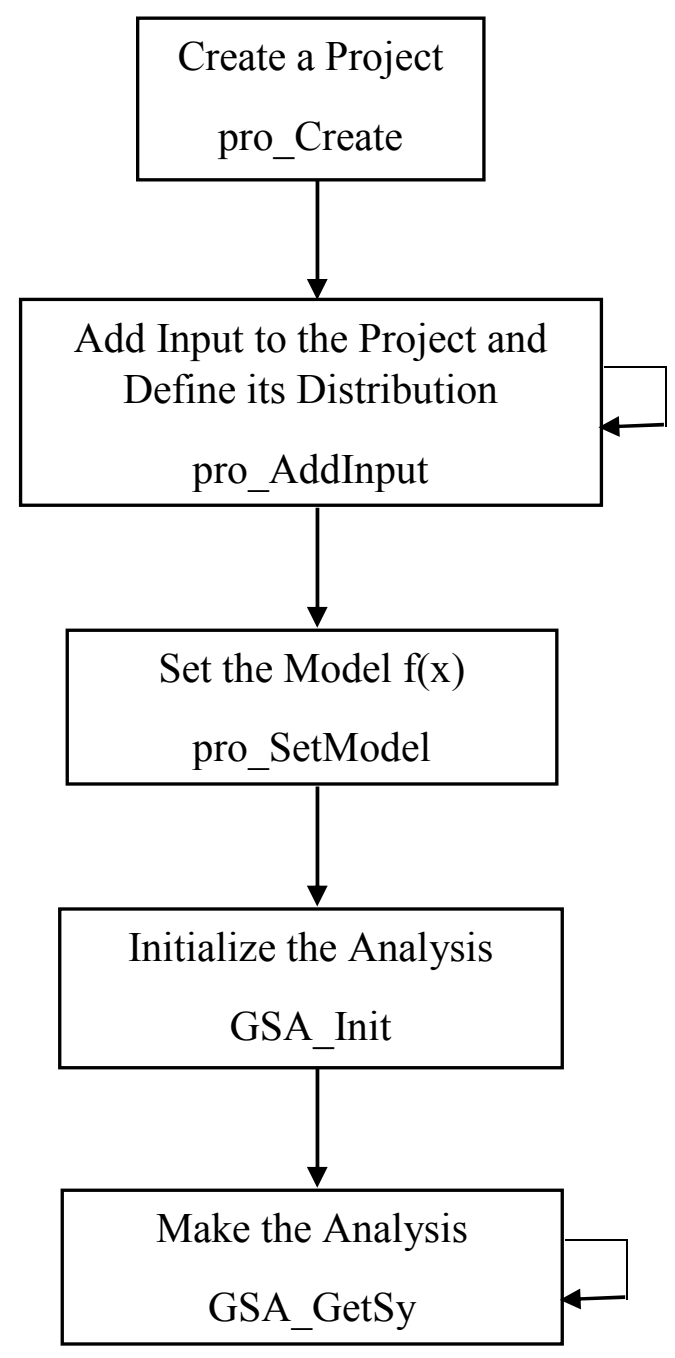

Figure 5 GSAT Toolbox for performing the Sensitivity Analysis

\subsubsection{Monte Carlo and quasi-Monte Carlo Algorithms}

Marcov Chain Monte Carlo is a simple procedure to simulate the stochastic processes by estimating a probability densities from a known distribution. Using a Monte Carlo approach, sampling from a very large number of samples is possible (Geyer, 1992). In this approach, each sample is considered as a new Markov chain which is repeated in a 
sampling series including steps of approval or disapproval (Moradkhani et al., 2012). The Monte Carlo method is widely used in the literature for solving integral and differential problems. For instance: in integration, Monte Carlo method is able to sample randomly from a known distribution and then the sample points considered to be the integration nodes (Morokoff and Caflisch, 1993). Also, this technique is considered as an accurate and efficient approach by the hydrologic modelers (DeChant and Moradkhani, 2014). However, Morokoff and Caflisch (1993) concluded that exchanging the Monte Carlo random sampling by a uniform distribution, can improve the convergence of the method and this new approach is known as Quasi-Monte Carlo approach.

The quasi-random sequences are introduced by Sobol' (1967) within a QuasiMonte Carlo approach. Moreover, Cannavó (2012) mentioned a drawback about the random sampling of Monte Carlo method that it encounters clustering dilemma in the sample space. In other words, in the sample space, there will be areas filled with points and others are empty. Therefore, it is quite possible that some areas in the sample space might be uncovered during the sampling process. For the mentioned reasons, the quasi-random sampling technique is preferred in this study. 


\section{Results}

\subsection{Importance of Model Input and Parameter Sensitivities (First-Order Effects)}

\subsubsection{Effect of Simulation Length on the Inputs Sensitivity of SAC-SMA Model}

The study covers three different simulation length: one-year period (Oct 2000-Oct 2001), four-year period (Oct 2000-Oct 2004), and seven-year period (Oct 2000-2007). The results of the main sensitivity effects for the one-year period for both sensitivity analysis methods (Sobol' and FAST) have almost the same trend for the five sub-basins. Figure 6 consists of bar-chart results for each sub-basin and one year period comparing Sobol' and FAST methods. From the figure, it can be seen that the tension water (LZTWM) and the primary withdrawal rate $(L Z P K)$ parameters in the lower zone are the most relevant parameters over all the sub-basins with maximum sensitivity values of 0.22 and 0.39 , respectively. It should be noted that the sensitivity index is a unitless index which ranges from zero to one (see section 3). However, the TW Sullivan has a slightly different result where the tension water maximum storage parameter in the upper zone (UZTWM) is also a sensitive parameter with sensitivity index of (0.17). The range of the sensitivity indices of both sensitivity analysis methods within this period varies from zero to 0.39 .

Figure 7 displays the results for the four-year period sensitivity analysis (main input effect). The four-year simulation results highlight some new parameters and input for some sub-basins as main contributors. For example, Sobol' method shows the precipitation input $(P)$ as a sensitive parameter in Milner and White Bird sub-basins (sensitivity indices of 0.4 and 0.37 , respectively). Another effective parameter over this time period is the UZTWM in TW Sullivan, Hungry Horse and White Bird sub-basins. The rest of the results are similar 
to the one-year period where the $L Z P K$ parameter is important in all sub-basins. The sensitivity indices within the four-year period reaches a maximum of 0.4 .
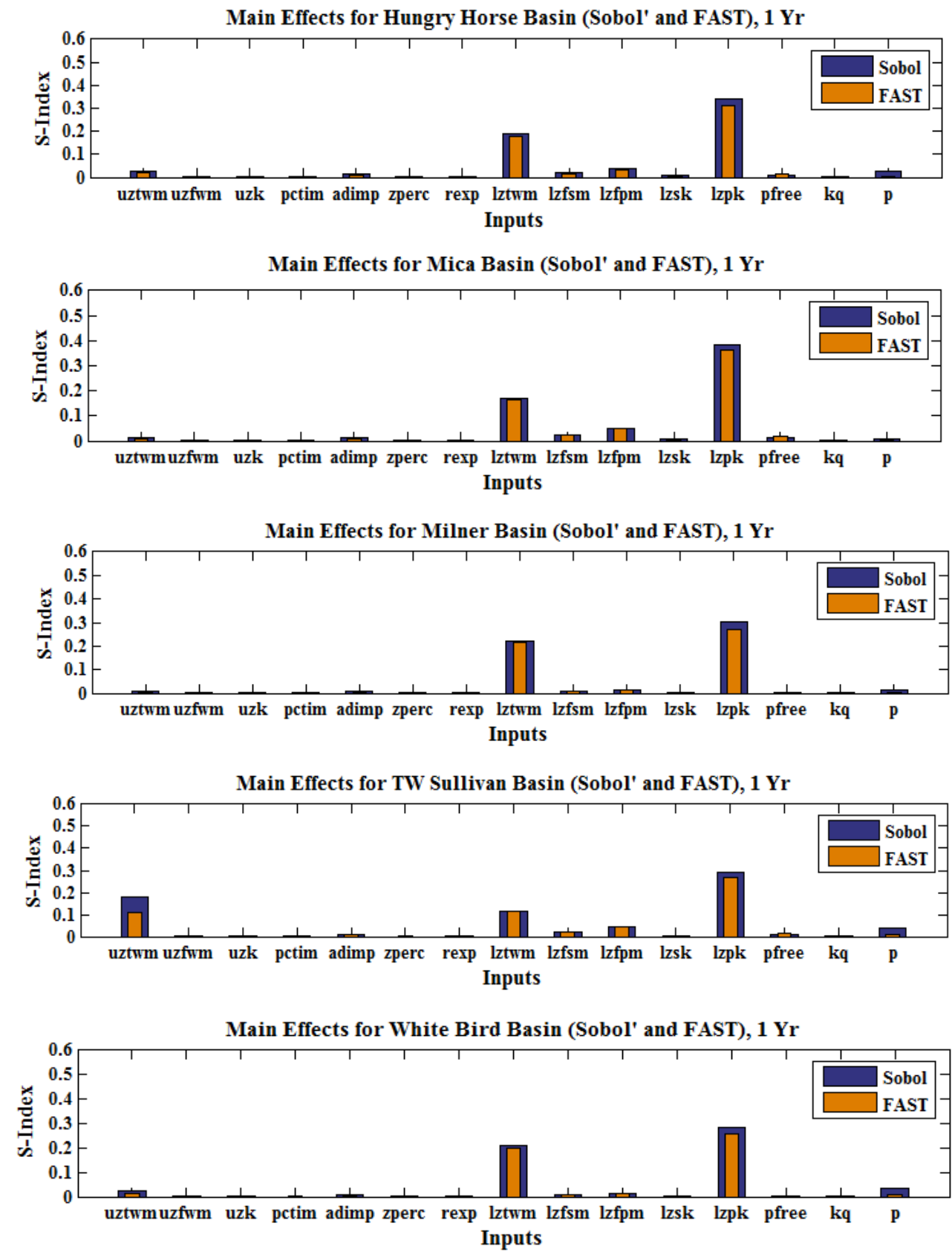

Figure 6 First-order sensitivity indices evaluated by the Sobol' and FAST sensitivity analysis methods for the one-year simulation period of the five sub-basins: Hungry Horse Sub-basin, Mica Sub-basin, Milner Sub-basin, TW Sullivan Sub-basin, and White Bird Sub-basin in CRB 

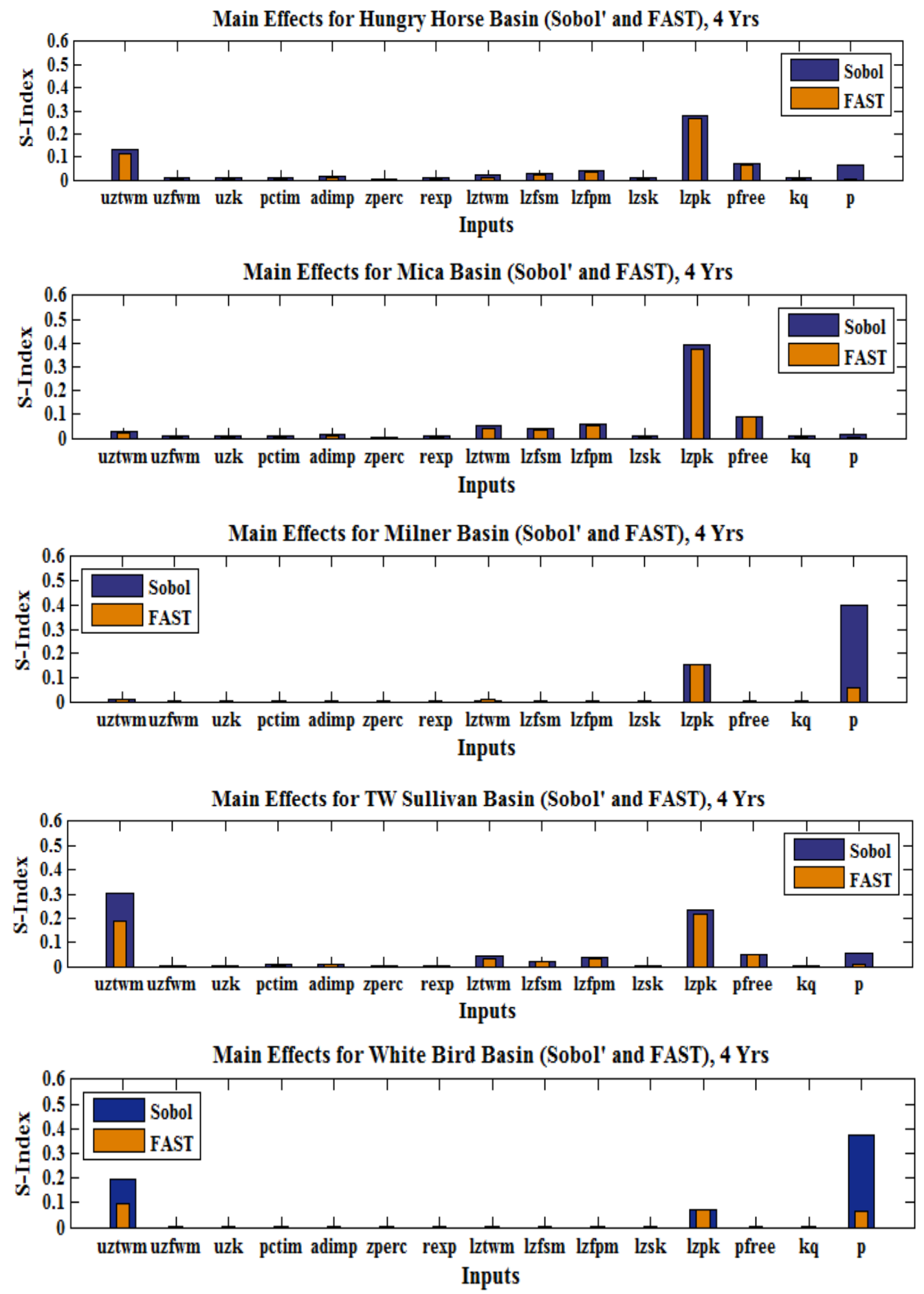

Figure 7 First-order sensitivity indices evaluated by the Sobol' and FAST sensitivity analysis methods for the four-year simulation period of the five sub-basins: Hungry Horse Sub-basin, Mica Sub-basin, Milner Sub-basin, TW Sullivan Sub-basin, and White Bird Sub-basin in CRB 
Figure 8 describes a comparison between the Sobol' and FAST methods results for the seven-year period. Generally, From Figure 8, it is noted that the SAC-SMA model parameters and input sensitivity results are closer to the four-year period results (Figure 7). The reason can be the effect of model warming up. The warming up period of a model is the initial phase that is required for the system to stabilize (Kolahi, 2011). Apparently, the four sub-basins: Hungry Horse, Milner, TW Sullivan, and White Bird sensitivity analysis results are quite similar to the four-year period results, however the LZPK sensitivity degree is less in Milner and White Bird sub-basins. For Mica sub-basin, the results are different than the other time periods where the $U Z T W M$ and $P$ are marked as sensitive. The maximum sensitivity value reached in this period is about $(0.56)$ for the $(P)$ in Milner subbasin.

Color maps are used to compare the Sobol' and FAST main effect sensitivities. Figure 9 shows the main effects of Sobol' and FAST for different simulation lengths over all the sub-basins. In most cases, the results show coherence in highlighting the same parameters and input as the major contributors to the model output variance. However, the one-year simulation period results are different than the other periods by introducing the LZTWM parameter as the sensitive parameter. Furthermore, the $L Z P K$ parameter is the sensitive parameter in all sub-basins especially in Mica sub-basin for the one-year and fouryear periods (Figure 9). The $P$ input is marked to be important within the four-year and seven-year simulations in Milner and White Bird sub-basins. Also, most of the sub-basins have the $U Z T W M$ parameter as sensitive except during the one-year length period. One more point to highlight in Figure 9 is that the range of the sensitivity indices (the degree of 
parameter importance) differs from sub-basin to sub-basin and even differs during different simulation periods. For example, the highest sensitivity index is reached during the sevenyear period (0.56) in Milner sub-basin for the $P$ input while it is about (0.4) for the $P$ in the four-year period.
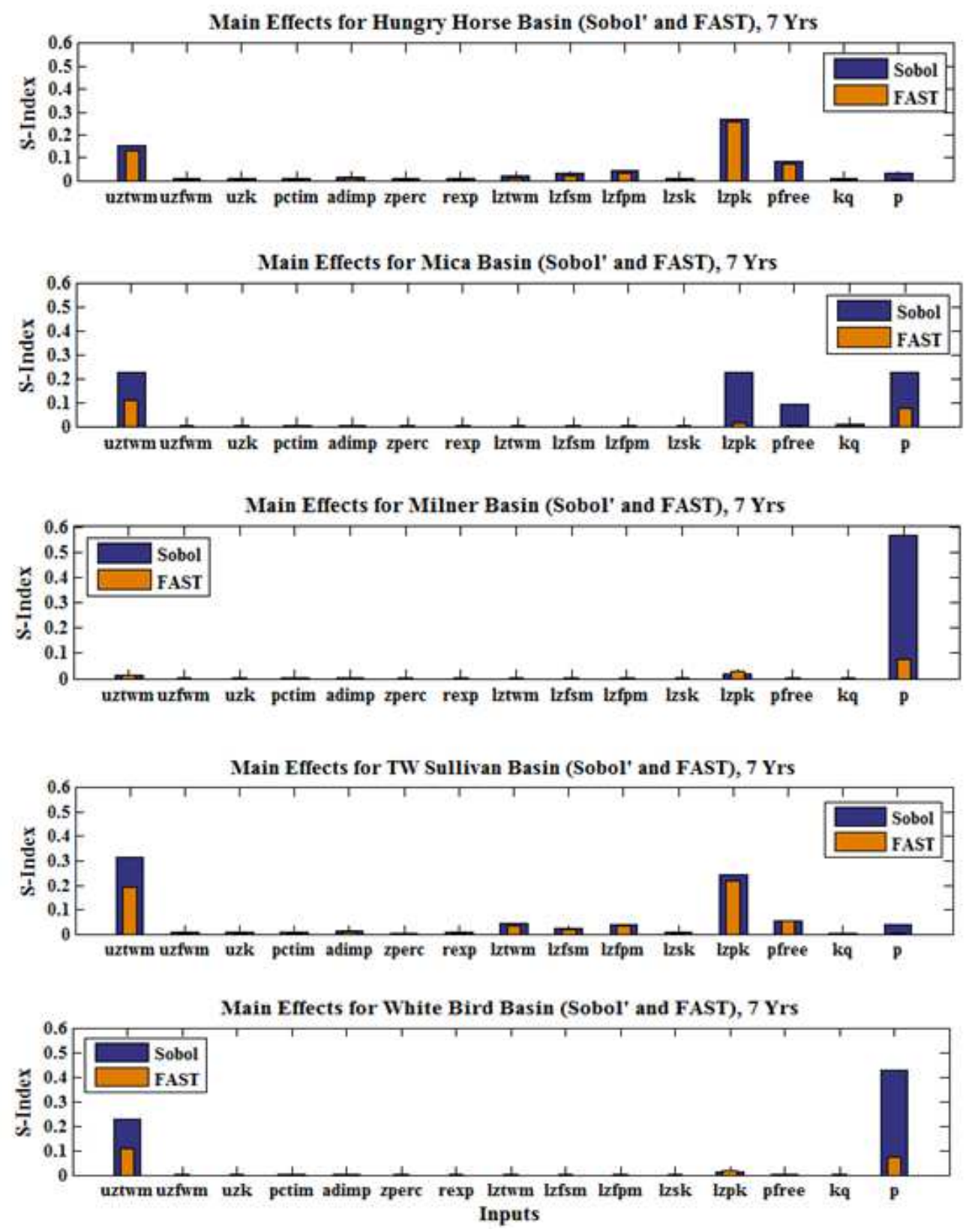

Figure 8 First-order sensitivity indices evaluated by the Sobol' and FAST sensitivity analysis methods for the seven-year simulation period of the five sub-basins: Hungry Horse Sub-basin, Mica Sub-basin, Milner Sub-basin, TW Sullivan Sub-basin, and White Bird Sub-basin in CRB 
Sobol' Main Effects for Five Basins, 1 Yr
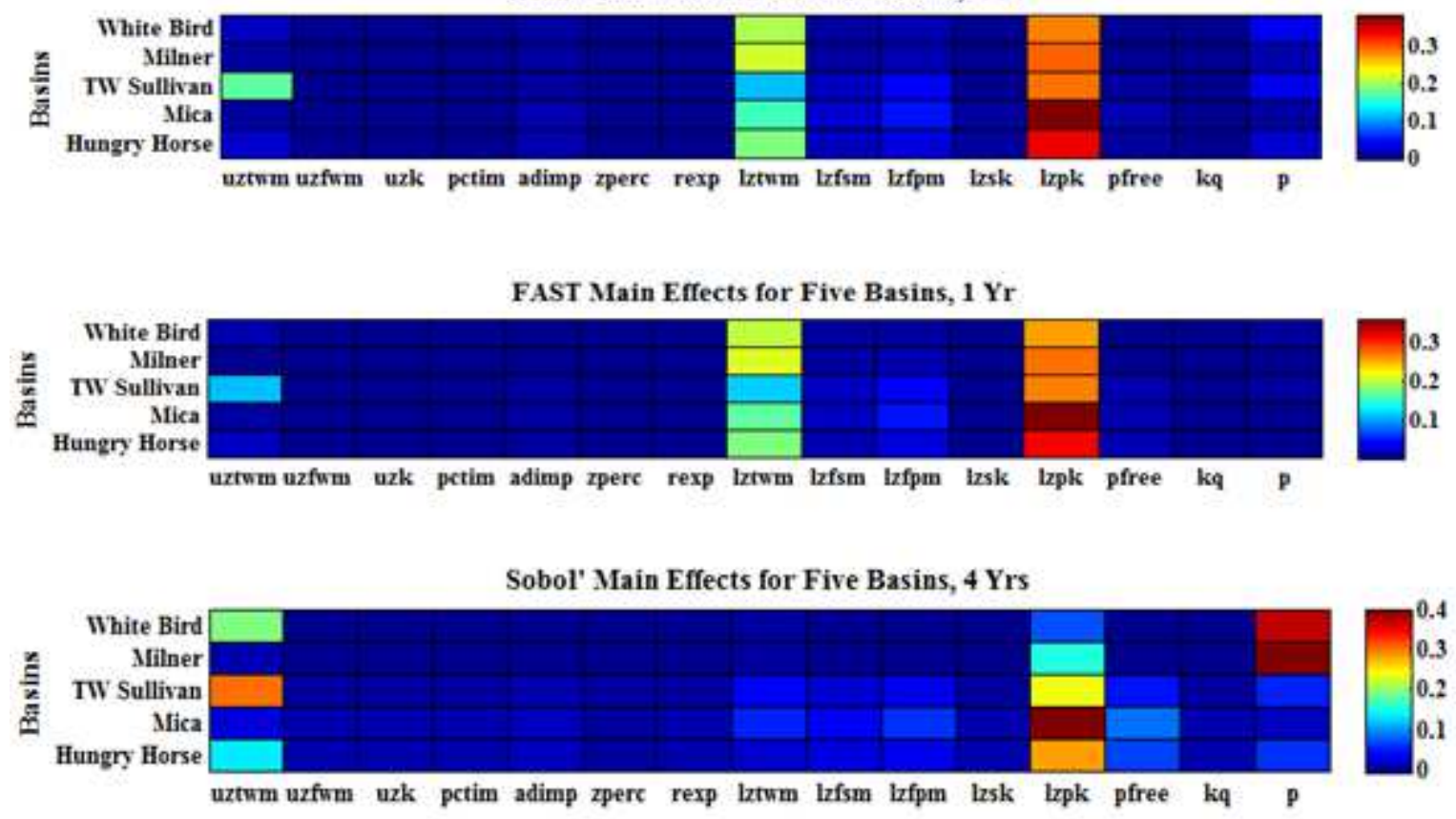

FAST Main Effects for Five Basins, 4 Yrs

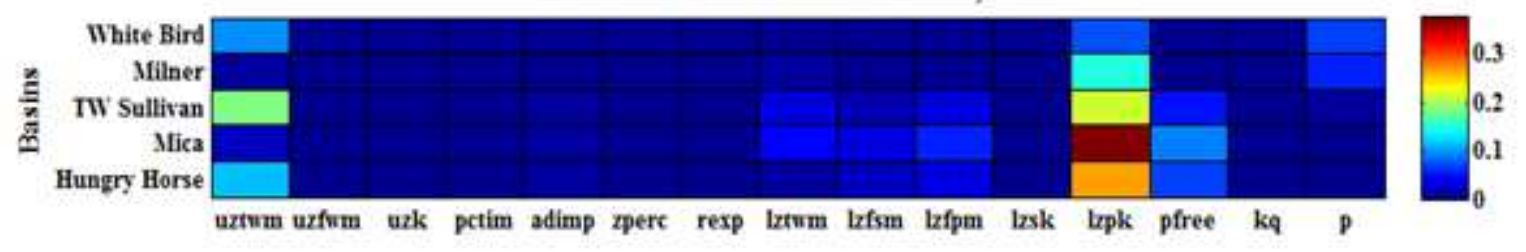

Sobol' Interaction Effects for Five Basins, 7 Yrs

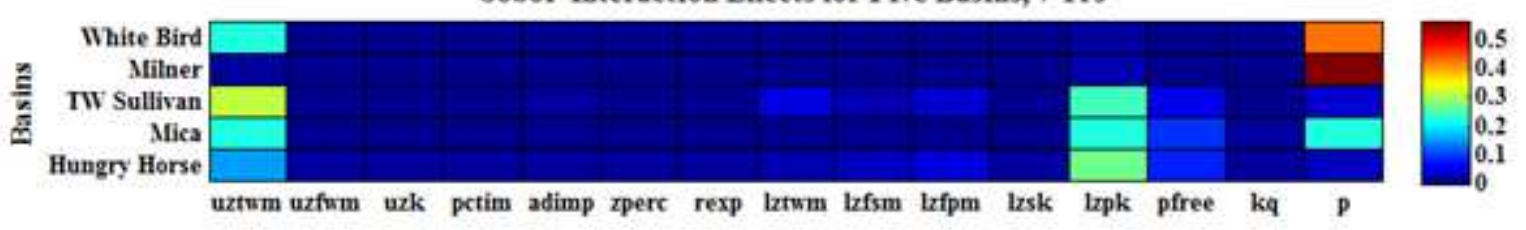

FAST Main Effects for Five Basins, 7 Yrs

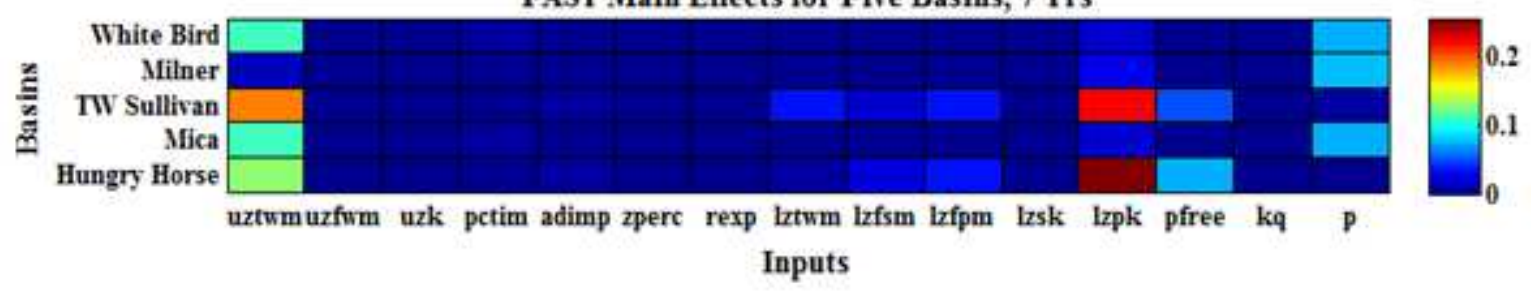

Figure 9 Parameter sensitivity calculated with the Sobol' and FAST sensitivity analysis methods for five sub-basins for different simulation lengths: Oct 2000-Oct 2001, Oct 2000-Oct 2004, and Oct 2000-Oct 2007 


\subsubsection{Comparing the Reliability of Sobol' and FAST Sensitivity Analysis Methods}

One of the objectives of this study is to evaluate the robustness and reliability of the GSA methods (Sobol' and FAST) that are used in this research. The reliability of the sensitivity methods is based on the comparison of the differences between the sensitivity indices which are estimated using Sobol' and FAST methods. Figures 10, 11, and 12 display the differences between sensitivity indices of FAST and Sobol' methods over all the sub-basins within different periods: (Oct 2000-Oct 2001), (Oct 2000-Oct 2004), and (Oct 2000-Oct 2007). In general, it is seen that both sensitivity analysis methods have agreement on the important parameters and input. The Sobol' sensitivity indices are higher than FAST in most cases (Figure 10), however, it does not mean FAST indices are systematically lower than Sobol' indices. For the one-year period, the difference between Sobol' and FAST indices is less than 0.1 (slight difference) in TW Sullivan sub-basin as shown in Figure 10. Whereas the difference is about 0.5 in Milner and White Bird subbasins during the four-year and seven-year simulation periods. A difference of (0.5) is considered a large difference that affects the sensitivity analysis result. In other words, such difference can change the degree of importance of certain parameter from being unimportant to be a very important parameter.

Other ways to evaluate the robustness of the sensitivity analysis methods are 1) to see the agreement between the two sensitivity analysis methods (Sobol' and FAST) in terms of highlighting the same parameters or input as the most sensitive ones and 2) how the methods are alike in ranking these sensitive parameters or input under the same conditions (sub-basins and simulation length). Table 2, 3, and 4 represent a comparison of 
the sensitivity mismatching results between the two methods obtained within different evaluation periods and sub-basins in the CRB. The tables show that for each sensitivity analysis method results, the important parameters and input are introduced regarding their degree of importance within the three simulation periods. For different simulation periods, only 5 of SAC-SMA parameters (UZTWM, LZTWM, LZFPM, LZPK, and PFREE) and the input $(P)$ are pop-up as sensitive ones. However, not all of these parameters and input are marked as important simultaneously. For example, from Table 2, only 3 or 4 parameters are important in each sub-basin. The numbers in the mentioned tables represent the rank of that parameter or input in each analysis.

The results of one-year evaluation period show no discrepancy in marking and ranking the important parameters and input for Sobol' and FAST methods (Table 2). Nevertheless, for the four-year and seven-year periods, five mismatching results appeared; two of them are a result of highlighting discrepancy and the other three as a result of ranking discrepancy. For instance, from Table 4, Sobol' method highlighted three parameters (UZTWM, LZPK, and PFREE) and the input $(P)$ as sensitive in Mica sub-basin whereas FAST only highlighted one parameter $(U Z T W M)$ and the input $(P)$. That was a mismatching between the two methods regarding to mark the same parameters or input as relevant. In addition, the order of the $U Z T W M$ and $P$ in both methods was different and thus, this was the second mismatching criterion in this study. In the mentioned example, the total number of mismatching criteria is 3 and so forth. Although there are few differences, the overall results of the reliability and robustness of the sensitivity analysis methods, are consistent for both Sobol' and FAST methods. 
FAST vs. Sobol' Sensitivity Indices, 1 Year
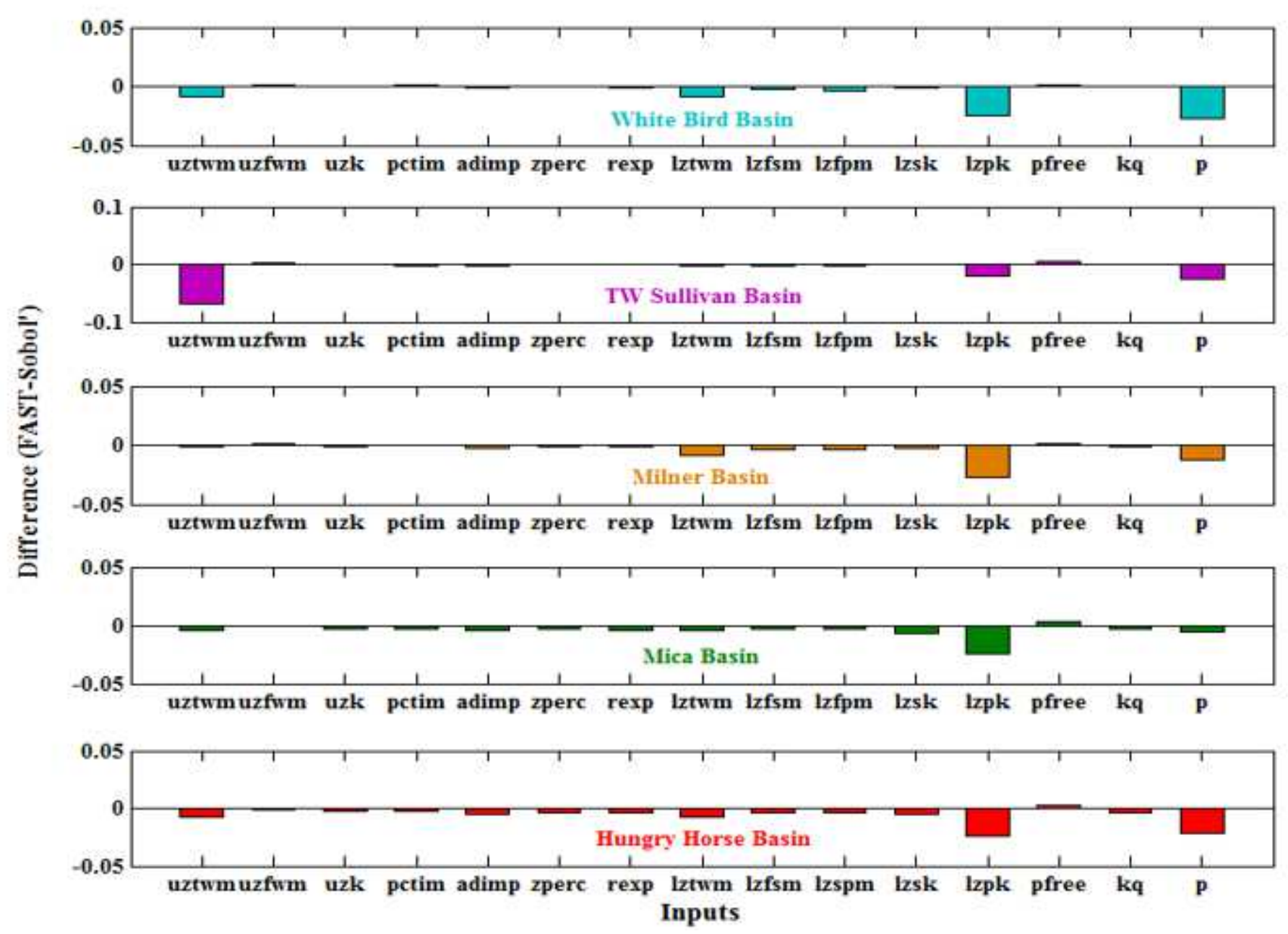

Figure 10 Difference between sensitivity indices of FAST and Sobol' methods during the period of (Oct 2000-Oct 2001) 


\section{FAST vs. Sobol' Sensitivity Indices, 4 Years}

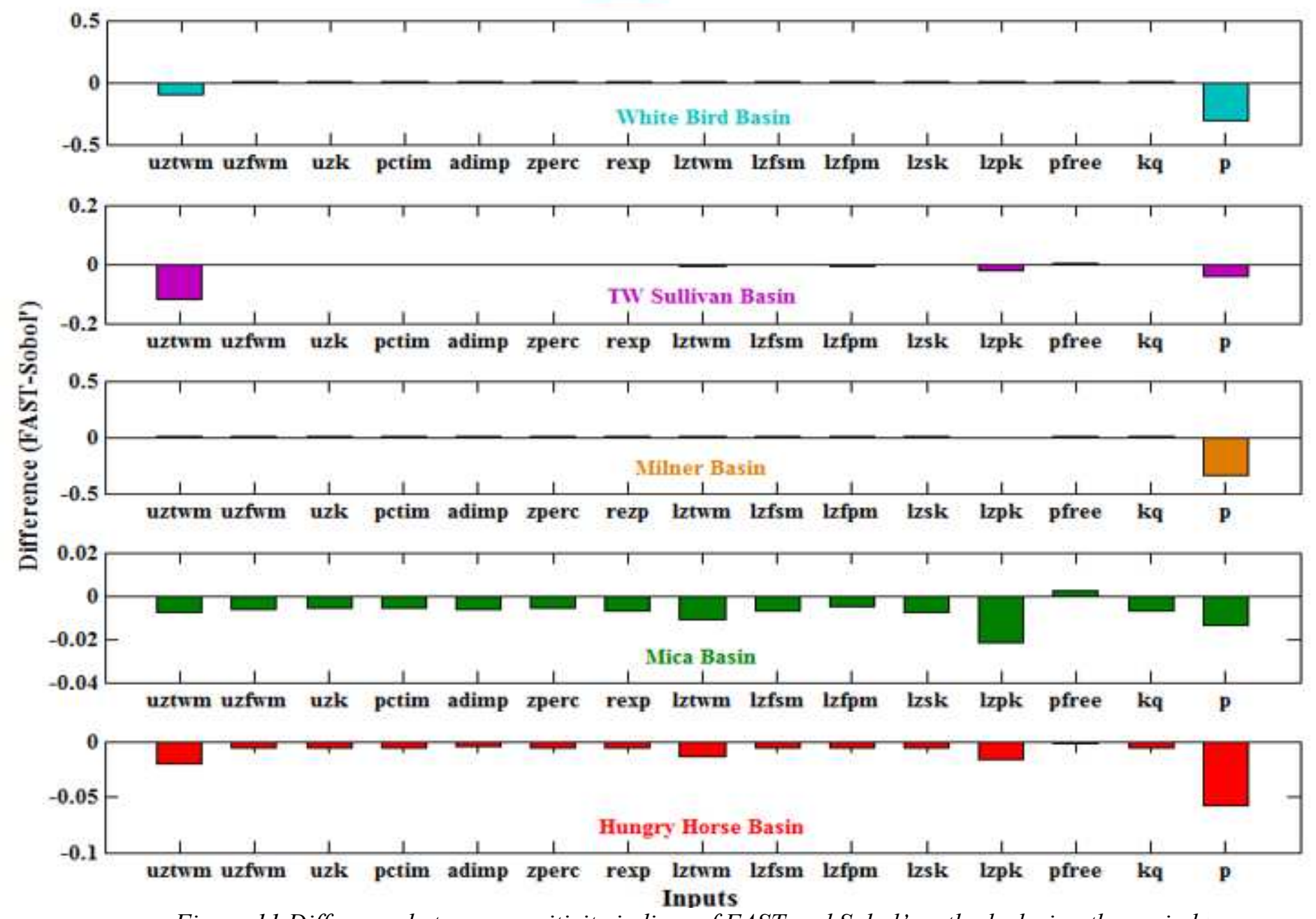

Figure 11 Difference between sensitivity indices of FAST and Sobol' methods during the period of (Oct 2000-Oct 2004) 
FAST vs. Sobol' Sensitivity Indices, 7 Years

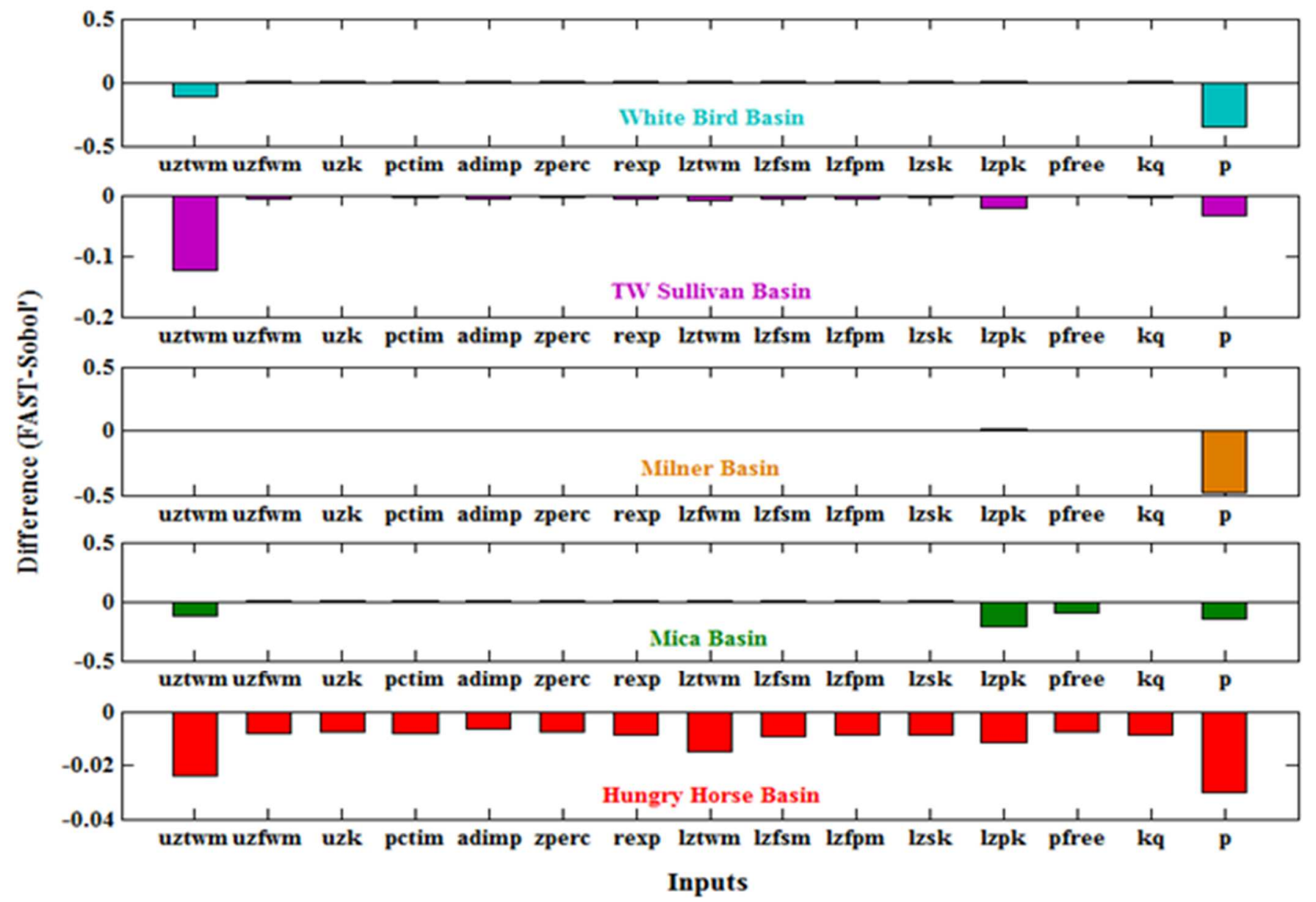

Figure 12 Difference between sensitivity indices of FAST and Sobol' methods during the period of (Oct 2000-Oct 2007) 
Table 3 Comparison of sensitivity evaluation based on the number of mismatching ranking or highlighting of sensitive parameters and input between the two sensitivity analysis methods obtained within four-year evaluation period for the five sub-basins in the CRB. Note that the numbers in the table indicate the rank/order.

\begin{tabular}{|c|c|c|c|c|c|c|c|c|c|c|}
\hline \multirow{2}{*}{ Basins } & \multicolumn{5}{|c|}{ Sobol' Sensitivity Evaluation (Importance Ranking) } & \multicolumn{5}{|c|}{ FAST Sensitivity Evaluation (Importance Ranking) } \\
\hline & $U Z T W M$ & $L Z T W M$ & LZFPM & $L Z P K$ & PFREE $P$ & $U Z T W M$ & $L Z T W M$ & LZFPM & $L Z P K$ & PFREE $P$ \\
\hline Hungry Horse & & 2 & 3 & 1 & & & 2 & 3 & 1 & \\
\hline Mica & & 2 & 3 & 1 & & & 2 & 3 & 1 & \\
\hline Milner & & 2 & & 1 & & & 2 & & 1 & \\
\hline TW Sullivan & 2 & 3 & 4 & 1 & & 2 & 3 & 4 & 1 & \\
\hline White Bird & & 2 & & 1 & & & 2 & & 1 & \\
\hline \multicolumn{11}{|c|}{ Number of Mismatching Ranking or Highlighting : 0} \\
\hline
\end{tabular}

Table 2 Comparison of sensitivity evaluation based on the number of mismatching ranking or highlighting of sensitive parameters and input between the two sensitivity analysis methods obtained within one-year evaluation period for the five sub-basins in the CRB. Note that the numbers in the table indicate the rank/order.

\begin{tabular}{|c|c|c|c|c|c|c|c|c|c|c|c|c|}
\hline \multirow{2}{*}{ Basins } & \multicolumn{6}{|c|}{ Sobol' Sensitivity Evaluation (Importance Ranking) } & \multicolumn{6}{|c|}{ FAST Sensitivity Evaluation (Importance Ranking) } \\
\hline & UZTWM & LZTWM & LZFPM & $L Z P K$ & PFREE & $P$ & UZTWM & LZTWM & LZFPM & $L Z P K$ & PFREE & $P$ \\
\hline Hungry Horse & 2 & & & 1 & 3 & 4 & 2 & & 4 & 1 & 3 & \\
\hline Mica & & 4 & 3 & 1 & 2 & & & 4 & 3 & 1 & 2 & \\
\hline Milner & & & & 2 & & 1 & & & & 1 & & 2 \\
\hline TW Sullivan & 1 & & & 2 & & 3 & 2 & & & 1 & 3 & \\
\hline White Bird & 2 & & & 3 & & 1 & 1 & & & 2 & & 3 \\
\hline & & & Number of & lismatch & ng Rankin & $g$ or & ghting : & & & & & \\
\hline
\end{tabular}


Table 4 Comparison of sensitivity evaluation based on the number of mismatching ranking or highlighting of sensitive parameters and input between the two sensitivity analysis methods obtained within seven-year evaluation period for the five sub-basins in the CRB. Note that the numbers in the table indicate the rank/order.

\begin{tabular}{|c|c|c|c|c|c|c|c|c|c|c|c|c|}
\hline \multirow{2}{*}{ Basins } & \multicolumn{6}{|c|}{ Sobol' Sensitivity Evaluation (Importance Ranking) } & \multicolumn{6}{|c|}{ FAST Sensitivity Evaluation (Importance Ranking) } \\
\hline & UZTWM & $L Z T W M$ & LZFPM & $L Z P K$ & PFREE & $P$ & $U Z T W M$ & LZTWM & LZFPM & $L Z P K$ & PFREE & $P$ \\
\hline Hungry Horse & 2 & & & 1 & 3 & & 2 & & & 1 & 3 & \\
\hline Mica & 2 & & & 3 & 4 & 1 & 1 & & & & & $\sqrt{2}$ \\
\hline Milner & & & & 2 & & $\sqrt{1}$ & & & & 2 & & 1 \\
\hline TW Sullivan & 1 & & & 2 & 3 & & 2 & & & 1 & 3 & \\
\hline White Bird & 2 & & & & & 1 & 1 & & & & & 2 \\
\hline
\end{tabular}




\subsection{Effect of Input and Parameter Interactions on the Inputs Sensitivity of SAC-SMA Model}

Since the results of the four-year simulation period are close to the seven-year period, the interaction effects only are compared between the one-year and the seven-year periods. The interaction effects are estimated for the (15) hydrological model (SAC-SMA) parameters and one input for the two periods. The outcomes of the Sobol' second order sensitivity (interactions between two parameters) are similar to the Sobol' first order sensitivity (main parameter effect) within the periods of interest. Therefore, the four-year simulation period interactions results are not included in the thesis. The reason behind the coherence between the main and interaction parameter effects is that the combined effects of two important parameters are also important. Figure 13 and Figure 14 show color maps for the Sobol' interaction sensitivities for (15) parameters and one input during the oneyear and seven-year simulations, respectively.

From the main effects results for the one-year period, it is highlighted that $(L Z T W M)$ and $(L Z P K)$ parameters are the most relevant ones for all basins and the parameter $(U Z T W M)$ is another important parameter in the TW Sullivan sub-basin. Apparently, the results in this section confirm that the combined effects of two sensitive parameters are also important. From Figure 13, The joint effects of $(L Z T W M)$ and $(L Z P K)$ parameters are the most sensitive for all sub-basins, in which the sensitivity index exceeds (0.75) in Milner sub-basin. Also, the interactions effects between these parameters ( $L Z T W M$ and $L Z P K)$ and the other insensitive parameters are also marked as effective interactions as explained above (Figure 13). The sensitivity indices ranges (the degree of 
importance) are close for most sub-basins except for the TW Sullivan sub-basin which its maximum sensitivity range is less than the other sub-basins which is about $(0.5)$.

For the seven-year period, evidently, the precipitation $(P)$, the tension water maximum storage parameter in the upper zone (UZTWM) and the primary withdrawal rate $(L Z P K)$ input and parameters govern the interaction effects in (3) sub-basins: Mica, Milner, and White Bird. Moreover, $(U Z T W M)$ and $(L Z P K)$ parameters dominate the joint effects in Hungry Horse and TW Sullivan sub-basins (Figure 14). For this period, other color maps are presented for each sub-basin with only the (14) parameters of the SAC-SMA model because the $(P)$ input has high sensitivity indices in some sub-basins that prevent other parameters to be recognized as sensitive (Figure 15). After excluding the $(P)$ input for the seven-year period, new sensitive parameters occur in Milner sub-basin which are: (UZTWM) and (LZPK) parameters. However, the sensitivity index (degree of importance) for the new parameters are small (about 0.05). In general, the sensitivity ranges in Figure 15 are lower than the ones in Figure 14. For example, the sensitivity index is less than 0.6 in TW Sullivan sub-basin without including the $(P)$ input whereas it is greater than 0.8 in Milner sub-basin considering the $(P)$ input. 

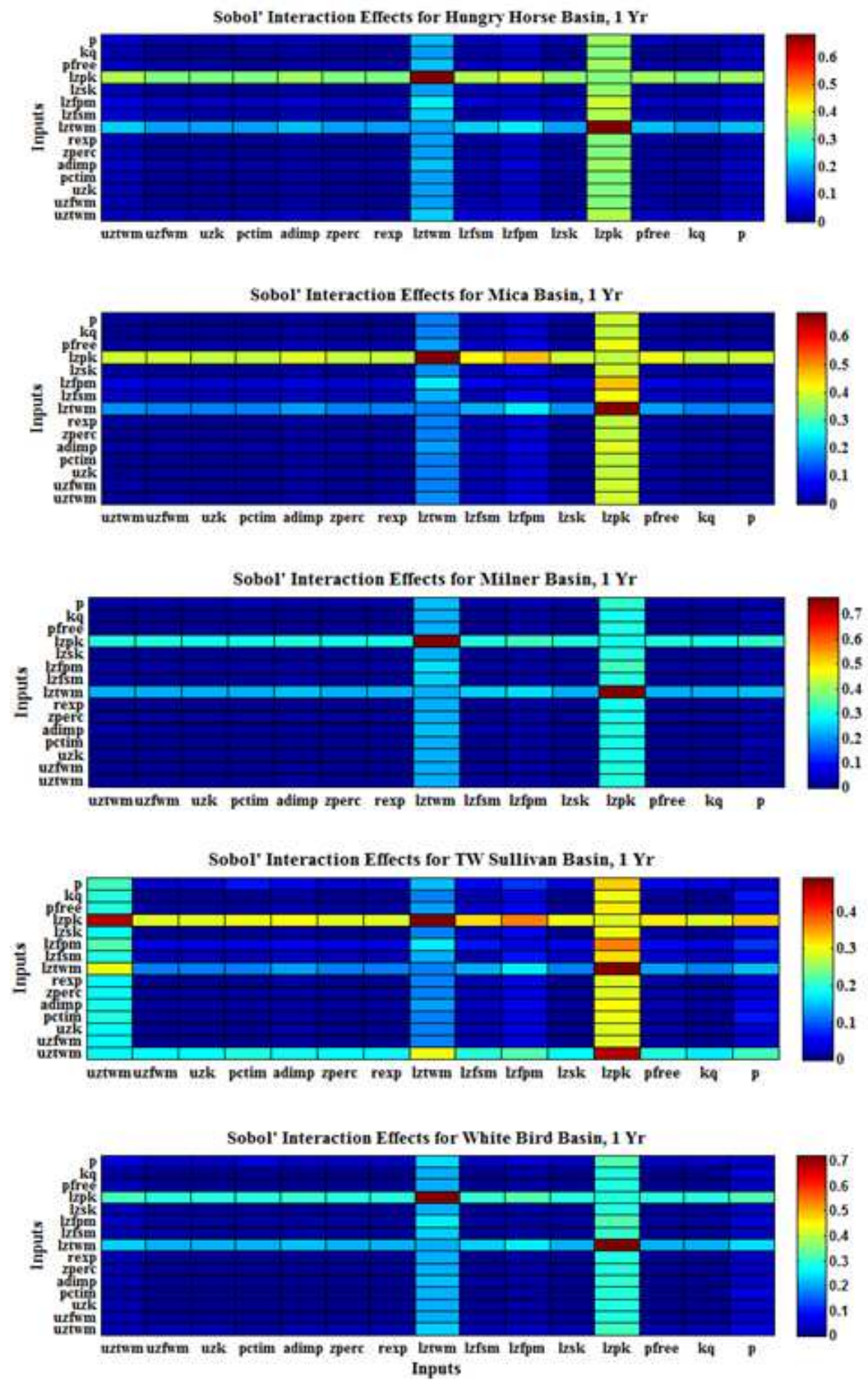

Figure 13 Parameters interactions calculated by the Sobol' (second-order) method for (15) inputs during the one-year simulation period for the five sub-basins of CRB 

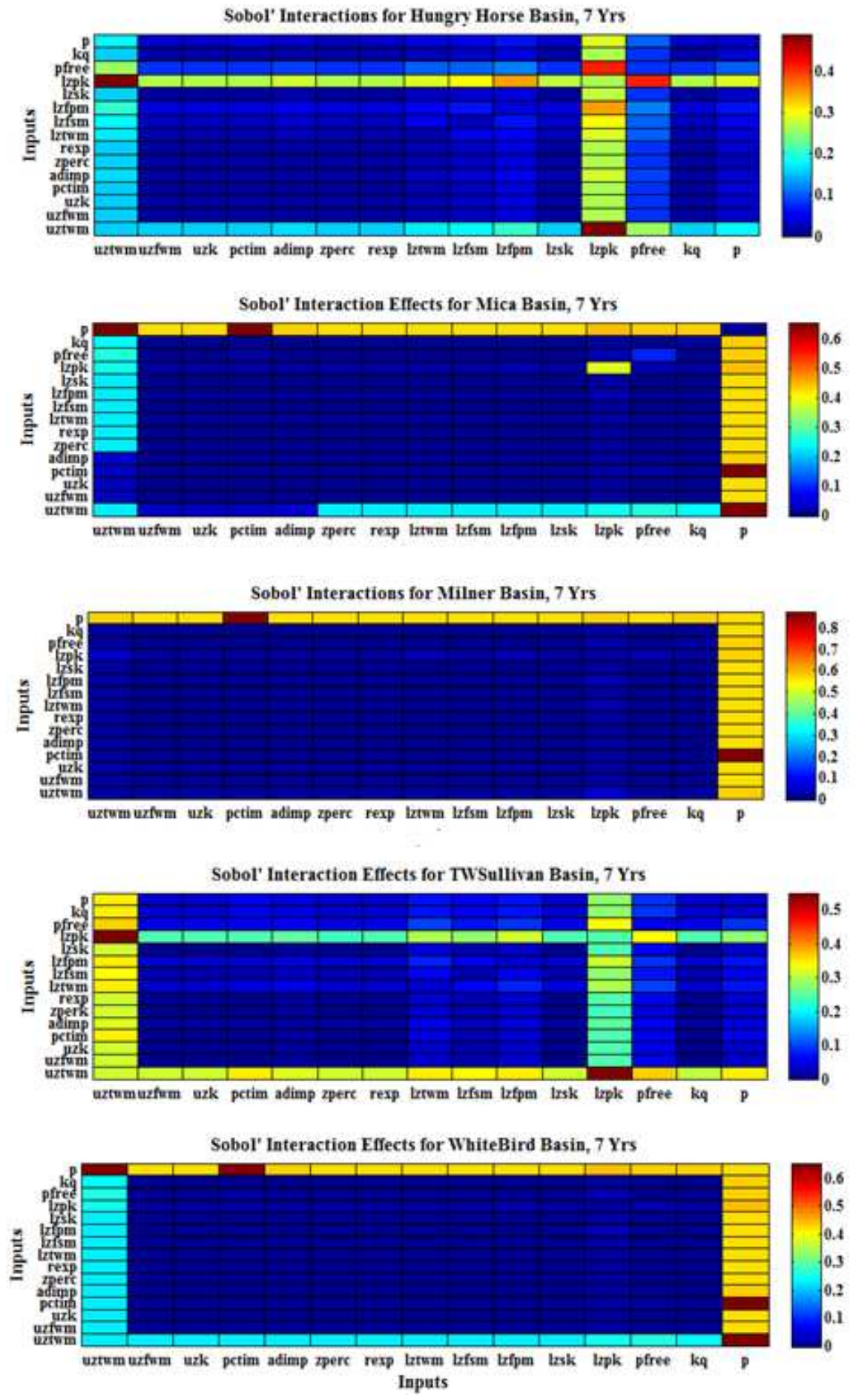

Figure 14 Parameters interactions calculated by the Sobol' (second-order) method for (15) inputs during the seven-year simulation period for the five sub-basins of CRB 

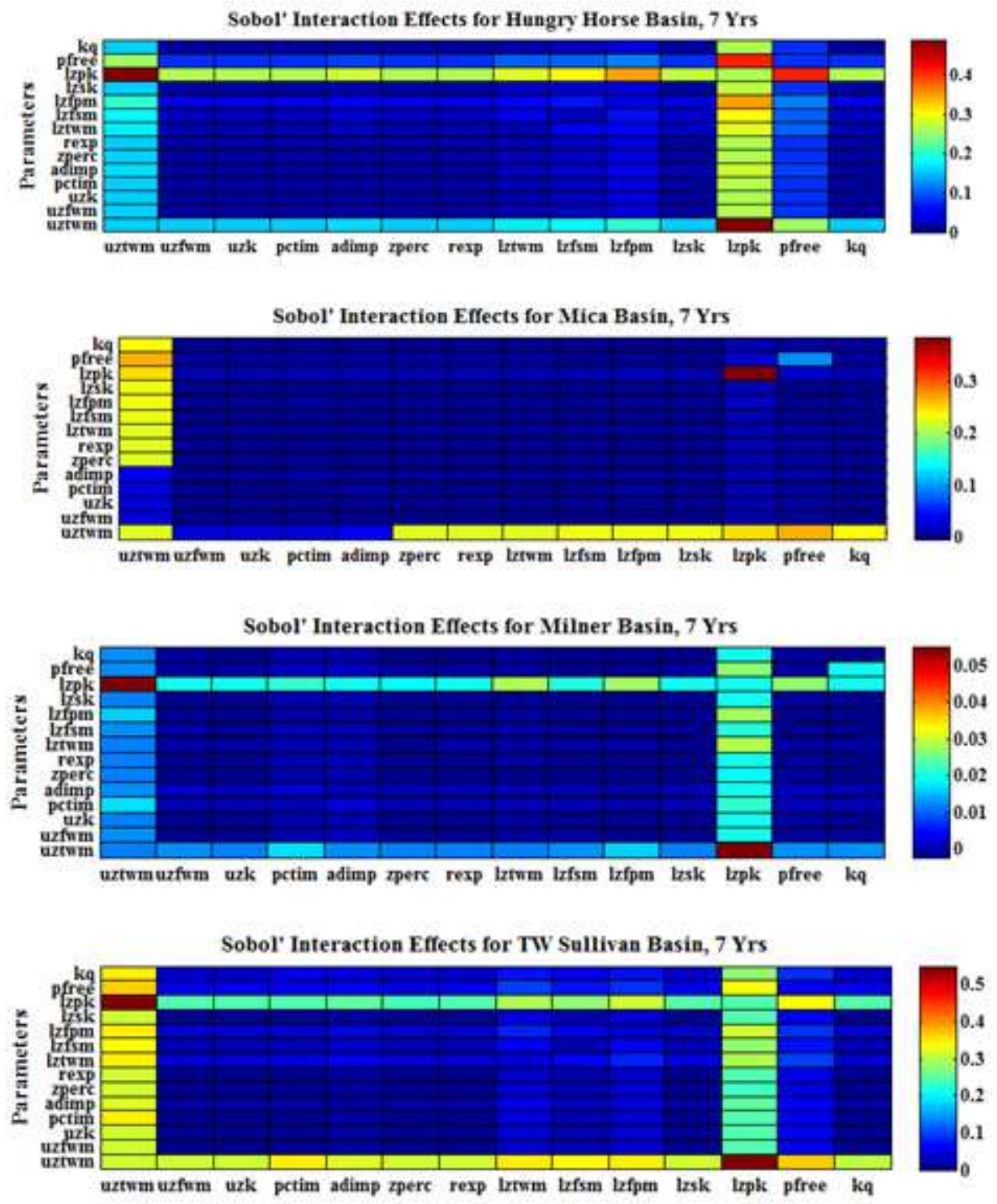

Sobol' Interaction Effects for White Bird Basin, 7 Yrs

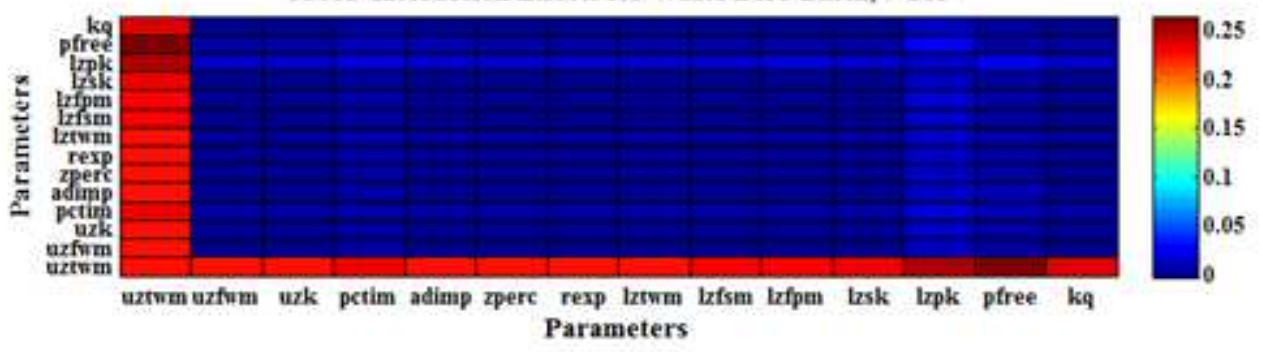

Figure 15 Parameters interactions calculated by the Sobol' (second-order) method for (14) inputs during the seven-year simulation period for the five sub-basins of CRB 


\section{Discussion}

The idea behind using two sensitivity analysis methods is to study whether their results are consistent or not. The results show that FAST method is more reasonable to use for evaluating the main effects of the model parameters and input, since it is computationally more efficient than Sobol' method. In this study, the time needed to obtain the main sensitivities results of $10^{4}$ runs by using Sobol' method on Windows system was about two weeks while by using FAST method was about two days. However, Sobol' method is very appealing that it can overcome the dimensionality dilemma (Saltelli et al., 1999).

In general, the results show coherence between the Sobol' and FAST sensitivity analysis methods. The two sensitivity methods reveal almost the same parameters and input as sensitive ones, however, the degree of importance is different in some cases. Table 5 shows the highest sensitivity indices for the one-year period. From the table, it can be seen that the results of the Sobol' and FAST methods are close. In terms of the reliability, only few results of the two sensitivity analysis methods do not match and most of these discrepancies are due to the ranking differences (Table 3 and 4). Furthermore, it is seen from the results in Figures 10, 11, and 12 that the Sobol' indices are higher than the FAST indices. Although both methods (Sobol' and FAST) are based on the ANOVA decomposition theory, the procedure of calculating the sensitivity indices is different for each method (section 3). 
Table 5 Summary of the highest sensitivity indices for the one-year period

\begin{tabular}{|c|c|c|c|c|c|}
\hline Basins & Geographic location & $\begin{array}{l}\text { Weather } \\
\text { condition }\end{array}$ & $\begin{array}{c}\text { Sobol' } \\
\text { Main Effect }\end{array}$ & $\begin{array}{c}\text { FAST } \\
\text { Main Effect }\end{array}$ & $\begin{array}{l}\text { Sobol' } \\
\text { Interaction } \\
\text { Effect }\end{array}$ \\
\hline Hungry Horse & $\begin{array}{l}\text { East CRB in } \\
\text { Montana/USA }\end{array}$ & $\begin{array}{l}\text { Rainfed } \\
\text { area }\end{array}$ & 0.34 & 0.31 & 0.68 \\
\hline Mica & $\begin{array}{l}\text { North CRB in British } \\
\text { Columbia/Canada }\end{array}$ & $\begin{array}{c}\text { Snow } \\
\text { dominated }\end{array}$ & 0.39 & 0.36 & 0.69 \\
\hline Milner & $\begin{array}{c}\text { Southeast CRB most the } \\
\text { sub-basin lies in } \\
\text { Idaho/USA }\end{array}$ & $\begin{array}{c}\text { Snow } \\
\text { dominated }\end{array}$ & 0.3 & 0.27 & 0.77 \\
\hline TW Sullivan & $\begin{array}{c}\text { Southwest CRB in } \\
\text { Oregon/USA }\end{array}$ & $\begin{array}{l}\text { Rainfed } \\
\text { area }\end{array}$ & 0.29 & 0.27 & 0.49 \\
\hline White Bird & $\begin{array}{l}\text { Central Southeast CRB in } \\
\text { Idaho/USA }\end{array}$ & $\begin{array}{c}\text { Snow } \\
\text { dominated }\end{array}$ & 0.28 & 0.26 & 0.72 \\
\hline
\end{tabular}

Table 6 shows a summary of the highest sensitivity indices for the seven-year period. The highest main sensitivity index reached is (0.56) for the precipitation (p) input in Milner sub-basin within the seven-year simulation period. The sensitivity index for the main effects varies mostly between (0-0.4) except for the $(P)$ input case. On the other hand, the indices for the interaction effects are much higher than the main effects where the ranges varied between (0-0.7) in most sub-basins and exceed (0.8) at Milner sub-basin during the longest period of this study as shown in Table 6. Thus, some parameters may not seem crucial by themselves but they can be effective once when they interact with other parameters. These results highlight the importance of specific processes of the SAC-SMA model as will be discussed in the next section. 
Table 6 Summary of the highest sensitivity indices for the seven-year period

\begin{tabular}{|c|c|c|c|c|c|}
\hline Basins & Geographic location & $\begin{array}{l}\text { Weather } \\
\text { condition }\end{array}$ & $\begin{array}{c}\text { Sobol' } \\
\text { Main Effect }\end{array}$ & $\begin{array}{c}\text { FAST } \\
\text { Main Effect }\end{array}$ & $\begin{array}{l}\text { Sobol' } \\
\text { Interaction } \\
\text { Effect }\end{array}$ \\
\hline Hungry Horse & $\begin{array}{l}\text { East CRB in } \\
\text { Montana/USA }\end{array}$ & $\begin{array}{l}\text { Rainfed } \\
\text { area }\end{array}$ & 0.27 & 0.26 & 0.49 \\
\hline Mica & $\begin{array}{l}\text { North CRB in British } \\
\text { Columbia/Canada }\end{array}$ & $\begin{array}{c}\text { Snow } \\
\text { dominated }\end{array}$ & 0.23 & 0.12 & 0.66 \\
\hline Milner & $\begin{array}{l}\text { Southeast CRB most the } \\
\text { sub-basin lies in } \\
\text { Idaho/USA }\end{array}$ & $\begin{array}{c}\text { Snow } \\
\text { dominated }\end{array}$ & 0.56 & 0.08 & 0.88 \\
\hline TW Sullivan & $\begin{array}{c}\text { Southwest CRB in } \\
\text { Oregon/USA }\end{array}$ & $\begin{array}{l}\text { Rainfed } \\
\text { area }\end{array}$ & 0.31 & 0.22 & 0.55 \\
\hline White Bird & $\begin{array}{l}\text { Central Southeast CRB } \\
\text { in Idaho/USA }\end{array}$ & $\begin{array}{c}\text { Snow } \\
\text { dominated }\end{array}$ & 0.43 & 0.12 & 0.66 \\
\hline
\end{tabular}

\subsection{Physical Interpretations the Consistency of the Sensitivity Analysis Results}

In the previous sections, the evaluation of the two sensitivity analysis is based on the statistical concepts, therefore, this section explains the results using the physical interpretations of the screened (sensitive) parameters and input. Jung et al, (2012) state that the regional geological and hydroclimatologic properties are highly connected to the hydrological process, therefore, understanding the meteorological conditions and the geographic nature of the study area is important step to link the results to the real-world case. The study area as mentioned earlier covers five sub-basins of the CRB in both sides: Canadian and USA. The five sub-basins are: Hungry Horse, Mica, Milner, TW Sullivan, and White Bird where all the sub-basins except TW Sullivan lie along the Rocky Mountains as shown in Figure 2. It is important to highlight that some hydrological processes are highly affected by the simulation length. Therefore, it can be noticed that the results of the one-year period are slightly different than the other periods.

For the one-year period, the lower zone parameters are more sensitive than the upper zone ones. Further, all the sub-basins show that the tension water (LZTWM) and the 
primary withdrawal rate $(L Z P K)$ parameters in the lower zone are the most influential parameters (Figure 6). The most likely reason is that the soil profile is saturated in these regions and with time it is expected to have the overland flow case. Therefore, when the simulation length increases (e.g. seven-year period), the tension water maximum storage parameter in the upper zone $(U Z T W M)$ is highlighted as sensitive where this parameter controls the soil moisture of the soil and the surface water runoff (Figure 8). This is from the fact that the snow cover increases the runoff amount due to snow melting which means it increases the soil moisture content (Massmann and Holzmann, 2012).

The results for the seven-year evaluation period confirm this finding by highlighting the precipitation $(P)$ as an important input in these sub-basins. Other interesting results in the seven-year period are that the tension water maximum storage parameter in the upper zone (UZTWM) parameter is marked as important parameter in Mica and White Bird sub-basin, however, in Milner sub-basin, this parameter is not important (Figure 8). This can be from the fact that Milner sub-basin is large and lies within an area influenced by complex surface water and ground-water interactions, therefore this could be the reason why this sub-basin shows different results than the other sub-basins. For Hungry Horse and TW Sullivan sub-basins, the results are similar during the seven-year period where the tension water maximum storage parameter in the upper zone (UZTWM) and the primary withdrawal rate $(L Z P K)$ parameters are relevant ones. The UZTWM parameter affects the over land flow and the water storage whereas the $L Z P K$ affects the baseflow processes. 
Moreover, these sub-basins are located in forested rainy areas where the water table is high and the soil is saturated. Obviously, in humid areas the infiltration capacity is high especially in vegetated regions, however overland flow can take place when the soil profile is already saturated. This is known as a saturation excess overland flow (Tarboton, 2003). One more point to highlight here is that most of the sub-basins lie at high elevations in which enhances the surface runoff state.

In summary, the natural elements of the real-world (e.g. meteorology and topography) play a major role in controlling the hydrological processes. As a result, it is essential to thoroughly investigate the study area before modeling. This will lead to better understanding the model behavior in that specific region. However, understanding all the physical behavior in small scale for any region is not an easy task. 


\section{Conclusions and Outlook}

In this study, the Global Sensitivity Analysis (GSA) is evaluated for the (SACSMA) hydrological model over the Columbia River Basin (CRB). The study is carried out for three different simulation periods by applying two sensitivity analysis methods: The Sobol' and FAST. The importance of 14 SAC-SMA model parameters and one input (forcing data) are estimated in five sub-basins within the CRB. As a first step, the main parameter sensitivities (first-order) are evaluated by using Sobol' and FAST methods. Then, the parameter interactions sensitivities (second-order) are obtained by Sobol' method. The results indicate coherence between the Sobol' and FAST sensitivity analysis methods. The reliability of the sensitivity analysis results is compared based on the main effects results. Here, it is seen that the results of the two methods are consistent in terms of highlighting and ranking the effective parameters and input. It is found that the ranges for the first-order sensitivities are lower than the second-order sensitivities. The explanation for this is that the Sobol' (second-order) sensitivity is the result of summing up the main effects of each parameter and their combined effect (Sobol, 2001).

For the main effects results, most of the sensitivity indices vary from zero to 0.5 in overall results, whereas the interactions indices vary from zero to 0.8 in most sub-basins. The results show that FAST method is sufficient to use for evaluating the main effects of the model parameters and input, especially, it is computationally more efficient than Sobol' method. Finally, the results of the sensitivity analysis are interpreted regarding their consistency with the physical meaning in the real-world case. Here, it is concluded that some hydrological processes are highly influenced by the simulation length. The model 
behavior during the one-year period differs than the other periods (four-year and sevenyear). For instance, the lower zone processes are more effective in the short period evaluations. It is explained that the soil profile is saturated and the water table is high in most of the sub-basins. Therefore, with time, it is expected to have the saturation from below case, it happens when the soil profile is saturated completely and the water table is high (Tarboton, 2003). Thus, the upper zone processes reveal to dominate the hydrological processes during the long term evaluations. This is explained due to the fact that in a soil with high moisture content (saturated), the overland flow process takes place which in turn is controlled by the upper zone parameters of the SAC-SMA model.

In conclusion, the Sobol' and FAST methods can be considered as reliable methods. The attractiveness is in their ability to quantitatively calculate the importance of model parameters and inputs. Thus, these sensitivity analysis methods help the modelers in decreasing the uncertainty dilemma associated with the model inputs (e.g. parameters, forcing data, and initial condition).

As a continuous work to this study, the focus will be on another important factor that can influence the sensitivity analysis results which is the parameter range. This factor needs to be studied since it is investigated only by limited studies. In this study, the SACSMA parameter ranges are chosen from the literature. Also, from the reliability stand point, it is important to do more research about the uncertainty associated with the sensitivity analysis approach. 


\section{References}

Bolch, T., B. Menounos, and R. Wheate, 2010, Landsat-based inventory of glaciers in western Canada, 1985-2005: Remote Sensing of Environment, v. 114, p. 127-137.

Burnash, R. J. C., R. L. Ferral, and R. A. McGuire, 1973, A generalized streamflow simulation system, conceptual modeling for digital computers.

Cannavó, F., 2012, Sensitivity analysis for volcanic source modeling quality assessment and model selection: Computers \& Geosciences, v. 44, p. 52-59.

Jung, I.-W., Chang, H., and Moradkhani, H., 2011: Quantifying uncertainty in urban flooding analysis considering hydro-climatic projection and urban development effects, Hydrol. Earth Syst. Sci., 15, 617-633, doi:10.5194/hess-15-617-2011.

Chang, H., and I.-W. Jung, 2010, Spatial and temporal changes in runoff caused by climate change in a complex large river basin in Oregon: Journal of Hydrology, v. 388, p. 186-207.

Confalonieri, R., G. Bellocchi, S. Bregaglio, M. Donatelli, and M. Acutis, 2010, Comparison of sensitivity analysis techniques: a case study with the rice model WARM: Ecological Modelling, v. 221, p. 1897-1906.

Cukier, R. I., C. M. Fortuin, K. E. Shuler, A. G. Petschek, and J. H. Schaibly, 1973, Study of the sensitivity of coupled reaction systems to uncertainties in rate coefficients. I Theory: The Journal of Chemical Physics, v. 59, p. 3873-3878.

Dajani, K., and S. Dirksin, 2008, A Simple Introduction to Ergodic Theory.

David Davidson and Jaymes McClain, "The Columbia River Treaty Review: A ynopsis," Border 
Policy Research Institute, Western Washington University, winter 2014. Accessed March 28, 2015.http://www.wwu.edu/bpri/files/2014_Winter_Border_Brief.pdf.

DeChant, C. M., and H. Moradkhani, 2012, Examining the effectiveness and robustness of sequential data assimilation methods for quantification of uncertainty in hydrologic forecasting: Water Resources Research, Res., 48, W04518, doi:10.1029/2011WR011011.

DeChant, C.M. and H. Moradkhani, 2014, Hydrologic Prediction and Uncertainty Quantification, Handbook of Engineering Hydrology, Modeling, Climate Change and Variability, CRC press, Taylor \& Francis Group, PP 387-414.

Dobler, C., and F. Pappenberger, 2013, Global sensitivity analyses for a complex hydrological model applied in an Alpine watershed: Hydrological Processes, v. 27, p. 3922-3940.

Ebtehaj, M., H. Moradkhani, and H. V. Gupta, 2010, Improving robustness of hydrologic parameter estimation by the use of moving block bootstrap resampling: Water Resources Research, 46, W07515, doi:10.1029/2009WR007981.

Encyclopædia Britannica. “Columbia River.” Accessed March 20, 2015. http://www.britannica.com/EBchecked/topic/126987/Columbia-River

Farnsworth, R. K., and E. S. Thompson, 1983, Mean monthly, seasonal, and annual pan evaporation for the United States, US Department of Commerce, National Oceanic and Atmospheric Administration, National Weather Service. 
Fierke, M. K., and J. B. Kauffman, 2005, Structural dynamics of riparian forests along a black cottonwood successional gradient: Forest Ecology and Management, v. 215, p. $149-162$.

Gan, Y., Q. Duan, W. Gong, C. Tong, Y. Sun, W. Chu, A. Ye, C. Miao, and Z. Di, 2014, A comprehensive evaluation of various sensitivity analysis methods: A case study with a hydrological model: Environmental Modelling \& Software, v. 51, p. 269285.

Geyer, C. J., 1992, Practical markov chain monte carlo: Statistical Science, p. 473-483.

Halmstad, A., M. R. Najafi, and H. Moradkhani, 2013, Analysis of precipitation extremes with the assessment of regional climate models over the Willamette River Basin, USA: Hydrological Processes, v. 27, p. 2579-2590.

Hamlet, A. F., and D. P. Lettenmaier, 1999, Effects of climate change on hydrology and water resources in the Columbia River Basin1, Wiley Online Library.

Hoekema, D. J., and V. Sridhar, 2011, Relating climatic attributes and water resources allocation: A study using surface water supply and soil moisture indices in the Snake River basin, Idaho: Water Resources Research, v. 47.

I.M. Sobol' , Sensitivity estimates for nonlinear mathematical models, Matem. Modelirovanie 2 (1) (1990) 112-118 (in Russian), MMCE, 1(4) (1993) 407-414 (in English).

Jost, G., R. D. Moore, B. Menounos, and R. Wheate, 2012, Quantifying the contribution of glacier runoff to streamflow in the upper Columbia River Basin, Canada: Hydrology and Earth System Sciences, v. 16, p. 849-860. 
Jung, I.-W., H. Moradkhani, and H. Chang, 2012, Uncertainty assessment of climate change impacts for hydrologically distinct river basins: Journal of Hydrology, 466467, p73-87, 10.1016/j.jhydrol.2012.08.002.

Kolahi, S. S., Simulation Model, 2011,Warm-up Period, and Simulation Length of Cellular Systems, p. 375-379.

Li, J. D., Q. Y. Duan, W. Gong, A. Z. Ye, Y. J. Dai, C. Y. Miao, Z. H. Di, C. Tong, and Y. W.

Lilburne, L., and S. Tarantola, 2009, Sensitivity analysis of spatial models: International Journal of Geographical Information Science, v. 23, p. 151-168.

Livneh, B., E. A. Rosenberg, C. Lin, B. Nijssen, V. Mishra, K. M. Andreadis, E. P. Maurer, and D. P. Lettenmaier, 2013: A Long-Term Hydrologically Based Dataset of Land Surface Fluxes and States for the Conterminous United States: Update and Extensions. J. Climate, 26, 9384 9392.

Massmann, C., and H. Holzmann, 2012, Analysis of the behavior of a rainfall-runoff model using three global sensitivity analysis methods evaluated at different temporal scales: Journal of Hydrology, v. 475, p. 97-110.

Matheussen, B., R. L. Kirschbaum, I. A. Goodman, G. M. O'Donnell, and D. P. Lettenmaier, 2000, Effects of land cover change on streamflow in the interior Columbia River Basin (USA and Canada): Hydrological Processes, v. 14, p. 867885.

Moradkhani, H., C. M. DeChant, and S. Sorooshian, 2012, Evolution of ensemble data assimilation for uncertainty quantification using the particle filter-Markov chain 
Monte Carlo method: Water Resources Research, 48,W12520, doi:10.1029/2012WR012144.

Moradkhani, H., and S. Sorooshian, 2008, General review of rainfall-runoff modeling: Model calibration, data assimilation, and uncertainty analysis, Hydrological Modelling and the Water Cycle, Coupling of the Atmospheric and Hydrological Models, Springer, Water Science and Technology Library, volume 63, Part 1, 1-24, DOI: $10.1007 / 978-3-540-77843-1-1$.

Morokoff, W. J., and R. E. Caflisch, 1993, A quasi-Monte Carlo approach to particle simulation of the heat equation: SIAM Journal on Numerical Analysis, v. 30, p. 1558-1573.

Najafi, M. R., H. Moradkhani, and I. W. Jung, 2011, Assessing the uncertainties of hydrologic model selection in climate change impact studies: Hydrological Processes, v. 25, p. 2814-2826.

Nossent, J., P. Elsen, and W. Bauwens, 2011, Sobol'sensitivity analysis of a complex environmental model: Environmental Modelling \& Software, v. 26, p. 1515-1525.

Peeters, L. J. M., G. M. Podger, T. Smith, T. Pickett, R. H. Bark, and S. M. Cuddy, 2014, Robust global sensitivity analysis of a river management model to assess nonlinear and interaction effects: Hydrology and Earth System Sciences, v. 18, p. 3777-3785.

Razavi, S., and H. V. Gupta, 2015, What do we mean by sensitivity analysis? The need for comprehensive characterization of 'Global'sensitivity in Earth and Environmental Systems Models: Water Resources Research.

Recreation.gov, “Hungry Horse reservoir.” Accessed March 29, 2015. 
http://www.recreation.gov/recreationalAreaDetails.do?contractCode=NRSO\&recAreaId= 135

Reusser, D. E., W. Buytaert, and E. Zehe, 2011, Temporal dynamics of model parameter sensitivity for computationally expensive models with the Fourier amplitude sensitivity test: Water Resources Research, v. 47.

Risley, J., H. Moradkhani, L. Hay, and S. Markstrom, 2011, Statistical comparisons of watershed-scale response to climate change in selected basins across the United States: Earth Interactions, v. 15, p. 1-26.

Saltelli, A., S. Tarantola, and K.-S. Chan, 1999, A quantitative model-independent method for global sensitivity analysis of model output: Technometrics, v. 41, p. 39-56.

Shamir, E., B. Imam, H. V. Gupta, and S. Sorooshian, 2005, Application of temporal streamflow descriptors in hydrologic model parameter estimation: Water resources research, v. 41 .

Shin, M.-J., J. H. A. Guillaume, B. F. W. Croke, and A. J. Jakeman, 2013, Addressing ten questions about conceptual rainfall-runoff models with global sensitivity analyses in R: Journal of Hydrology, v. 503, p. 135-152.

Sobol, I. M., 1967, On the distribution of points in a cube and the approximate evaluation of integrals: USSR Computational mathematics and mathematical physics, p. 86112.

Sobol, I. M., 2001, Global sensitivity indices for nonlinear mathematical models and their Monte Carlo estimates: Mathematics and computers in simulation, v. 55, p. 271280. 
Song, X., J. Zhang, C. Zhan, Y. Xuan, M. Ye, and C. Xu, 2015, Global sensitivity analysis in hydrological modeling: Review of concepts, methods, theoretical framework, and applications: Journal of Hydrology, v. 523, p. 739-757.

Sridhar, V., X. Jin, and W. T. A. Jaksa, 2013, Explaining the hydroclimatic variability and change in the Salmon River basin: Climate dynamics, v. 40, p. 1921-1937.

State of Montana, "Hungry Horse Sub-basin, Montana: Biological Impact Evaluation and Operational Constraints for a proposed 90,000-acre-foot withdrawal." Accessed March 15, 2015.http://dnrc.mt.gov/divisions/reserved-water-rights-compact commission/docs/cskt/2011_hhbiologicalconstraintsreport.pdf

Sun, 2013, Assessing parameter importance of the Common Land Model based on qualitative and quantitative sensitivity analysis: Hydrology and Earth System Sciences Discussions, v. 10, p. 2243-2286.

Sun, X. Y., L. T. H. Newham, B. F. W. Croke, and J. P. Norton, 2012, Three complementary methods for sensitivity analysis of a water quality model: Environmental Modelling \& Software, v. 37, p. 19-29.

Tarboton, D. G., 2003, Rainfall-runoff processes: Utah State University. United States Department of Agriculture (USDA), Flathead National Forest, "Hungry HorseReservoir.”Accessed28, 2015. http://www.fs.usda.gov/recarea/flathead/recreation/ohv/recarea/?recid=77701\&actid=42 U.S. Department of the Interior, "Flathead Basin Tribal Depletions Study." Accessed March 15, 2015. http://dnrc.mt.gov/divisions/reserved-water-rights-compact commission/docs/cskt/2013appendix 7bureauofreclamationmodelingreport.pdf. U.S. Department of the Interior, National Park Service, "Hungry Horse Dam Montana." 
Accessed March 29, 2015.

http://www.nps.gov/nr/travel/ReclamationDamsIrrigationProjectsAndPowerplants/Hungr y_Horse_Dam.html

van Werkhoven, K., T. Wagener, P. Reed, and Y. Tang, 2008, Characterization of watershed model behavior across a hydroclimatic gradient: Water Resources Research, v. 44.

Van Werkhoven, K., T. Wagener, P. Reed, and Y. Tang, 2009, Sensitivity-guided reduction of parametric dimensionality for multi-objective calibration of watershed models: Advances in Water Resources, v. 32, p. 1154-1169.

Vaze, J., D. A. Post, F. H. S. Chiew, J. M. Perraud, N. R. Viney, and J. Teng, 2010, Climate non-stationarity-validity of calibrated rainfall-runoff models for use in climate change studies: Journal of Hydrology, v. 394, p. 447-457.

Wainwright, H. M., S. Finsterle, Y. Jung, Q. Zhou, and J. T. Birkholzer, 2014, Making sense of global sensitivity analyses: Computers \& Geosciences, v. 65, p. 84-94.

Zhan, C.-s., X.-m. Song, J. Xia, and C. Tong, 2013, An efficient integrated approach for global sensitivity analysis of hydrological model parameters: Environmental Modelling \& Software, v. 41, p. 39-52. 